\title{
Modelling of the photooxidation of toluene: conceptual ideas for validating detailed mechanisms
}

\author{
V. Wagner ${ }^{1}$, M. E. Jenkin ${ }^{2}$, S. M. Saunders ${ }^{1,}$ *, J. Stanton ${ }^{1}$, K. Wirtz ${ }^{3}$, and M. J. Pilling ${ }^{1}$ \\ ${ }^{1}$ School of Chemistry, University of Leeds, Leeds LS2 9JT, UK \\ ${ }^{2}$ Imperial College, Silwood Park, Ascot, Berkshire SL5 7PY, UK \\ ${ }^{3}$ Centro de Estudios Ambientales del Mediterraneo, C. Charles R. Darwin 14, 46980 Paterna, Spain \\ *present address: School of Earth and Geographical Science, University of Western Australia, 6009, Western Australia
}

Received: 3 July 2002 - Published in Atmos. Chem. Phys. Discuss.: 5 August 2002

Revised: 25 November 2002 - Accepted: 4 December 2002 - Published: 3 February 2003

\begin{abstract}
Toluene photooxidation is chosen as an example to examine how simulations of smog-chamber experiments can be used to unravel shortcomings in detailed mechanisms and to provide information on complex reaction systems that will be crucial for the design of future validation experiments. The mechanism used in this study is extracted from the Master Chemical Mechanism Version 3 (MCM v3) and has been updated with new modules for cresol and $\gamma$ dicarbonyl chemistry. Model simulations are carried out for a toluene- $\mathrm{NO}_{\mathrm{x}}$ experiment undertaken at the European Photoreactor (EUPHORE). The comparison of the simulation with the experimental data reveals two fundamental shortcomings in the mechanism: $\mathrm{OH}$ production is too low by about $44 \%$, and the ozone concentration at the end of the experiment is over-predicted by $55 \%$. The radical budget was analysed to identify the key intermediates governing the radical transformation in the toluene system. Ring-opening products, particularly conjugated $\gamma$-dicarbonyls, were identified as dominant radical sources in the early stages of the experiment. The analysis of the time evolution of radical production points to a missing $\mathrm{OH}$ source that peaks when the system reaches highest reactivity. First generation products are also of major importance for the ozone production in the system. The analysis of the radical budget suggests two options to explain the concurrent under-prediction of $\mathrm{OH}$ and overprediction of ozone in the model: (1) missing oxidation processes that produce or regenerate $\mathrm{OH}$ without or with little $\mathrm{NO}$ to $\mathrm{NO}_{2}$ conversion or (2) $\mathrm{NO}_{3}$ chemistry that sequesters reactive nitrogen oxides into stable nitrogen compounds and at the same time produces peroxy radicals. Sensitivity analy-
\end{abstract}

Correspondence to: M. J. Pilling

(M.J.Pilling@chem.leeds.ac.uk sis was employed to identify significant contributors to ozone production and it is shown how this technique, in combination with ozone isopleth plots, can be used for the design of validation experiments.

\section{Introduction}

The photooxidation of aromatic hydrocarbons contributes significantly to the formation of urban photochemical smog. Detailed mechanisms are used to calculate photochemical ozone creation potentials (POCPs) for organic compounds that assist policy makers in defining realistic pollution control strategies (Derwent et al., 1998). Derwent et al. (1996) have shown from trajectory model calculations that about one third of the regional ozone production for a typical air mass in northwest Europe is caused by aromatics. In that study toluene is identified as the VOC with the highest ozone production along the trajectory, owing to a combination of high emissions and a comparatively high POCP value.

The oxidation of toluene proceeds via several channels that result either in ring-retaining or ring-opening products. The two prevailing ring-retaining routes, which form cresol and benzaldehyde as first generation products, are comparatively well understood (Atkinson, 1992; Klotz et al., 1998; Volkamer et al., 2002), whereas the chemistry of the ringopening routes is still very speculative (Smith et al., 1998; Volkamer et al., 2001; Yu and Jeffries, 1997). Over the past years several ring-opening routes have been proposed in line with emerging experimental information (Atkinson et al., 1980; Bartolotti and Edney, 1995; Klotz et al., 1997). 


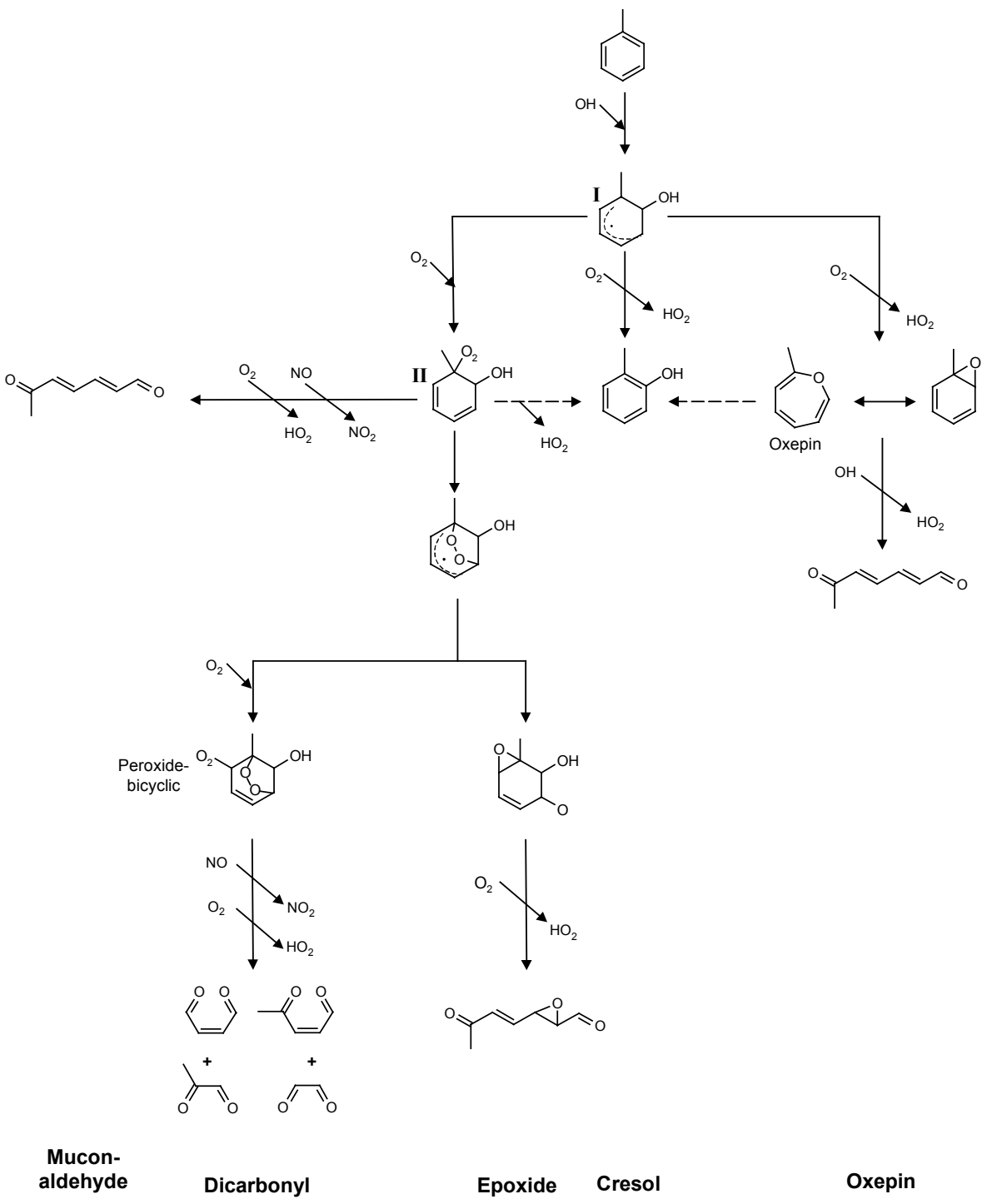

Fig. 1. Initial reaction steps of the $\mathrm{OH}$ initiated oxidation of toluene as discussed in current literature. Names at the bottom of the figure are labels for the reaction routes as used in this publication. Only major pathways that follow the addition of $\mathrm{OH}$ to the ring are considered, the quinone route $\left(1,4\right.$ addition of $\mathrm{OH}$ and $\left.\mathrm{O}_{2}\right)$ and the benzaldehyde route ( $\mathrm{H}$-abstraction from the methyl group) are not shown. The mechanisms of all routes are still very speculative. From the radical intermediates only the aromatic-OH adduct (I) and the hydroxycyclohexadienyl type peroxy radical (II) have been detected in laboratory experiments. Evidence for the epoxide route is very tentative, and all attempts to detect oxepin in toluene oxidation systems have failed so far. See text for further explanations.

This development, which is reflected in three versions of the MCM, is outlined in the following (Fig. 1 and Fig. 2).

Based on detection of ring-opening products, such as glyoxal and methylglyoxal, Atkinson et al. (1980) proposed a reaction channel (here labelled as dicarbonyl route) in which the ring breaks down via a series of peroxide-bicyclic intermediates eventually forming $\alpha$-dicarbonyls (glyoxal and methylglyoxal) and conjugated $\gamma$-dicarbonyls (butenedial, 2methylbutenedial and 4-oxo-2-pentenal). In the mid-nineties quantum mechanical calculations published by Bartolotti and Edney (1995) suggested that an epoxide-type compound is the most stable intermediate following the $\mathrm{OH}$ addition to the ring. This result shifted the attention to a reaction pathway (termed hereon as epoxide route) in which epoxides are the dominant reaction products. Following this direction, $\mathrm{Yu}$ and Jeffries (1997) were indeed able to find experimental evidence for this route by detecting compounds with molecular weights matching a series of putative epoxide intermediates. A further reaction route was proposed based on observations of prompt $\mathrm{HO}_{2}$ formation at high yields in the toluene and benzene oxidation system by flash photolysis experiments (Klotz et al., 1997). These high yields of direct $\mathrm{HO}_{2}$ for- 


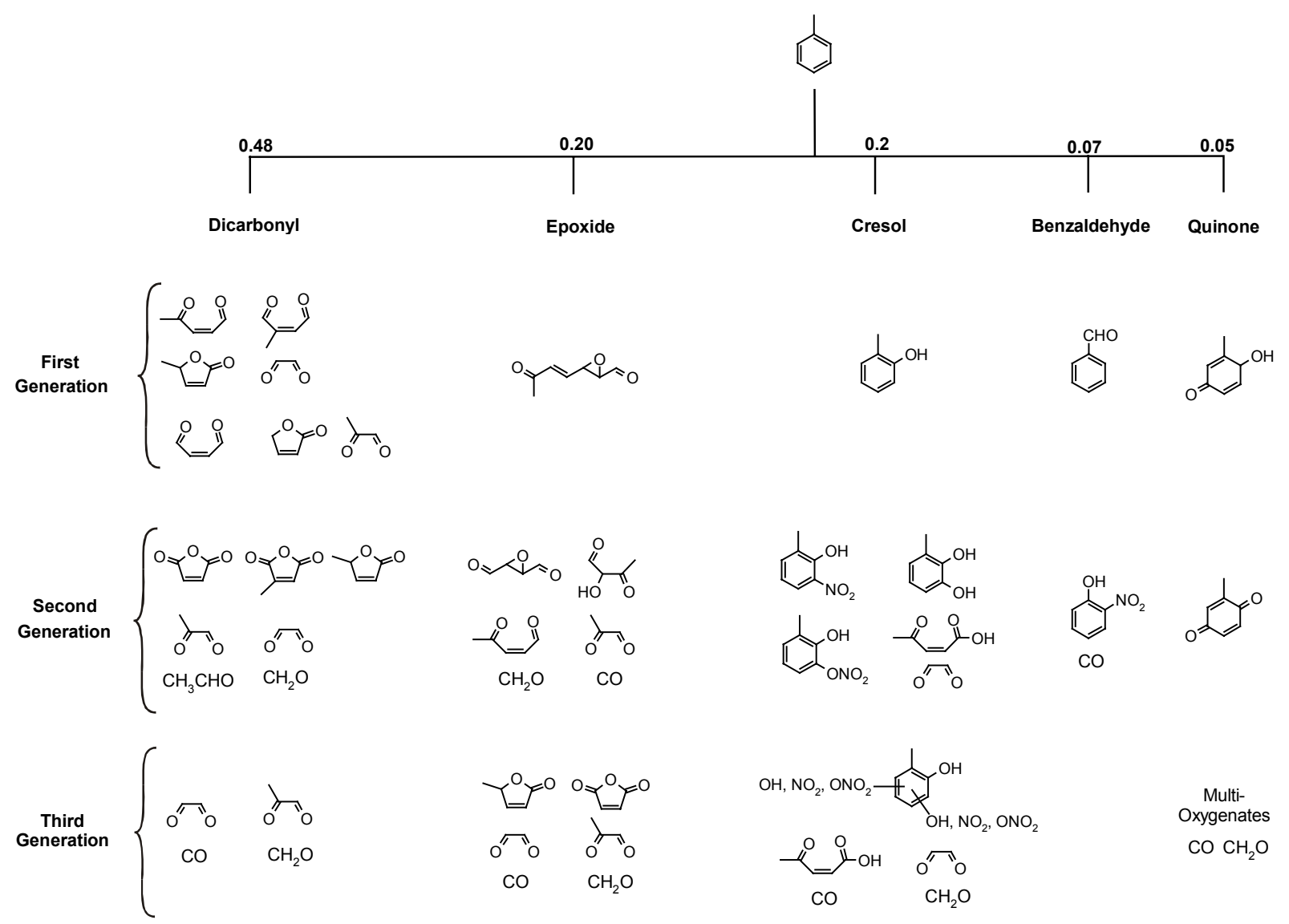

Fig. 2. Major reaction products in the toluene photooxidation system as implemented in the TOL_MCM3a model used in this study $\left(\mathrm{CO}_{2}\right.$ is not shown). Note, branching ratios for ring-opening routes are speculative, particularly for the epoxide-route as for this pathway only qualitative evidence exists.

mation, without an $\mathrm{NO}$ to $\mathrm{NO}_{2}$ conversion step, indicated a further reaction channel, in addition to the phenol route, that produces prompt $\mathrm{HO}_{2}$ (Klotz et al., 2000; Bohn and Zetsch, 1999; Bohn, 2001). Based on these findings Klotz et al. (1997) suggested an aromatic oxide/oxepin route with muconaldehydes as ring-opening products and prompt $\mathrm{HO}_{2}$ production. The mechanism for this route was developed by analogy with the metabolism of benzene. Berndt et al. (1999) carried out an experimental study to investigate this reaction pathway, but no evidence for the formation of aromatic oxide/oxepin could be found.

Owing to a lack of quantitative information on ringopening products, branching ratios for the ring-opening pathways have not yet been established. However, most quantitative evidence has been found for intermediates that are consistent with the ring-opening route proposed by Atkinson et al. (1980).

A number of mechanisms have been developed to describe the photooxidation of aromatic compounds (Liang and Jacobson, 2000). They show varying degrees of explicit treatment. With 670 implemented reactions for the photooxidation of toluene, the MCMv3 aims to reflect the most detailed current knowledge in the field of toluene photo-oxidation (http://www.chem.leeds.ac.uk/ Atmospheric/MCM/mcmproj.html). According to the historic development in the field of aromatic photooxidation, the MCM v1, launched in 1997, contained a toluene mechanism based mainly on a ring-opening route as proposed by Atkinson et al. (1980). For MCM v2 a toluene mechanism was developed that explored the proposed degradation route involving the formation of aromatic oxide/oxepin intermediates (Klotz et al., 2000). Subsequently, as no evidence could be found for significant contribution from the aromatic oxide/oxepin route (Berndt et al., 1999), this channel has been replaced in the MCM $\vee 3$ by dicarbonyl and epoxide routes.

In comparisons with smog-chamber data, the MCM v1 toluene mechanism over-predicts $\left[\mathrm{O}_{3}\right]$ by a factor of around 2 (Liang and Jacobson, 2000). The MCM v2, on the other hand, shows too little photochemical reactivity and underpredicts $\mathrm{O}_{3}$ formation significantly if compared to toluene smog-chamber experiments (this study, unpublished results). The MCM $v 3$ predicts time-concentration profiles for $\mathrm{NO}_{\mathrm{x}}$ 
$\left(\mathrm{NO}_{\mathrm{x}}=\mathrm{NO}+\mathrm{NO}_{2}\right), \mathrm{O}_{3}$ and toluene that are in comparatively good agreement with smog-chamber data, but there is still a tendency to over-predict the ozone concentration by around $50 \%$.

Over the past few years the MCM was constantly upgraded to keep up with the growing body of mechanistic detail on aromatic oxidation provided by kinetic studies. The implemented mechanisms have been highly speculative in part, particularly for the ring-opening routes. Owing to a lack of data for model validation and of techniques to analyze the effects of new mechanistic details on the $\mathrm{RO}_{\mathrm{x}}$ and $\mathrm{NO}_{\mathrm{y}}$ budgets, on-line checks of the effects of these changes on the overall performance of the mechanism were not possible $\left(\mathrm{RO}_{\mathrm{x}}=\mathrm{OH}+\mathrm{HO}_{2}+\right.$ organic oxy radicals $(\mathrm{RO})+$ organic peroxy radicals $\left(\mathrm{RO}_{2}\right) ; \mathrm{NO}_{\mathrm{y}}=\mathrm{NO}+\mathrm{NO}_{2}+\mathrm{NO}_{3}+\mathrm{HONO}+$ $\mathrm{HNO}_{3}+$ peroxy acyl nitrates $\left(\mathrm{PAN}_{\mathrm{y}}\right)+$ organic peroxy nitrates $\left(\mathrm{RO}_{2} \mathrm{NO}_{2}\right)+$ organic nitrates $\left.\left(\mathrm{RONO}_{2}\right)\right)$. Thus, the procedure of mechanism development was hampered resulting in mechanisms that show large discrepancies in varying directions, if tested against recently available smog-chamber data.

This paper aims to give an overview of the status of toluene modelling based on a master chemical mechanism. Information on the major shortcomings of the current mechanism is derived from a comparison of model simulations with smogchamber data. These shortcomings are tracked down to radical transformation within the mechanism. With the aid of a radical budget calculation, we identify the key intermediates that dominate radical production in smog-chamber toluene experiments and that provide the crucial information needed to develop future validation strategies. Furthermore, processes governing ozone production in the system are analysed and a sensitivity analysis is employed to identify the intermediates that have the highest impact on ozone production. The assembled information gives a precise description of areas where further research is needed to overcome current shortcomings in the mechanism and shows how modelling can become an interactive tool in mechanism development.

\section{The mechanism}

The toluene mechanism used for all calculations is extracted from the MCMv3 and has been modified according to recently available information on mechanistic details. In the following we will refer to this mechanism as TOL_MCM3a. A complete listing of reactions, rate coefficients and photolysis rates is available on the world wide web at http: //www.chem.leeds.ac.uk/Atmospheric/intro.html. As for all VOCs treated by the MCM v3, the toluene mechanism is constructed according to a master chemical mechanism protocol (Jenkin et al., 2002). The framework of the mechanism is based on literature data on product yields, rate coefficients and photolysis rates of intermediates in the toluene oxidation system. Where no experimental data is available, kinetic parameters are calculated using the principle of structure activity relationship (e.g. Atkinson, 1987; Kwok and Atkinson, 1995). Particularly for the ring-opening routes, the quantitative information on reaction products and their photochemical fate is still very scarce (Smith et al., 1998; Yu and Jeffries, 1997; Yu et al., 1997). Hence the implemented oxidation chemistry of these routes is very speculative.

Owing to the constantly growing amount of information on reactions relevant to toluene oxidation, it lies in the nature of any detailed mechanism that it remains always in an evolutionary state of development. For this reason the applied TOL_MCM3a mechanism shows deviations in a number of mechanistic details from the MCM v3. The only major differences that significantly affect radical production of the system are (1) photolysis of conjugated $\gamma$-dicarbonyls and (2) the oxidation of cresol.

1. In the MCMv3, generic photolysis rates are applied for the photolysis of conjugated $\gamma$-dicarbonyls derived from experimental data published by Sørensen et al. (1998), Liu et al. (1999) and Bierbach et al. (1994). For two $\gamma$-dicarbonyls, butenedial and 4-oxo-2-pentenal, which are oxidation products of toluene, experimental data are available (Sørensen et al., 1998) and we have set the photolysis rates for all $\gamma$-dicarbonyls in TOL_MCM3a accordingly. These changes result in a higher rate of production of $\mathrm{RO}_{\mathrm{x}}$ radicals and generally increase the oxidation capacity of the toluene reaction system.

2. The $\mathrm{OH}$-initiated oxidation of cresol in the MCM v3 is mainly described by a ring-opening route with a yield of $95 \%$. Recent experiments on the reaction of $\mathrm{OH}$ with cresol have shown that the branching ratio for this route is far lower and depends strongly on the cresol isomer (Olariu et al., 2002). Based on this information we estimated an upper limit for the ring-opening route for the reaction of $\mathrm{OH}$ with cresol of $28 \%$ and changed the mechanism in the TOL_MCM3a model accordingly. The products of the ring-retaining routes are multifunctional compounds containing a combination of $-\mathrm{NO}_{2}$, $-\mathrm{ONO}_{2}$ and $-\mathrm{OH}$ groups. The main effect of the higher branching ratio for ring-retaining products is therefore a sequestering of $\mathrm{NO}_{\mathrm{x}}$ into nitro- and nitrooxy-aromatics, which in turn means a lower $\mathrm{O}_{3}$ production potential of the aromatic oxidation system. Furthermore, reactions of $\mathrm{NO}_{3}$ with cresol and its substituted isomers are implemented. These reactions become an important sink for cresol and for $\mathrm{NO}_{\mathrm{x}}$ in the later stages of smogchamber experiments when, due to low NO levels, the $\mathrm{NO}_{3}$ concentration increases to some $\mathrm{pmol} / \mathrm{mol}$.

In TOL_MCM3a, toluene oxidation is represented by 229 species and 676 reactions, describing the breakdown of the carbon skeleton. The $\mathrm{OH}$-initiated oxidation of toluene proceeds via 5 reaction channels, which are labelled according 
to the most prominent reaction products (Fig. 2). The dicarbonyl and the epoxide routes proceed via opening of the aromatic ring in the first reaction step. The branching ratio has not been measured for either of these routes. In the model they together account for $67 \%$ of the total toluene oxidation that is not covered by ring-retaining routes. Based on available data a dicarbonyl:epoxide ratio of 7:3 was adopted, reflecting the different amounts of experimental evidence for the two routes.

In the dicarbonyl route the aromatic ring breaks down into $\alpha$-dicarbonyls (glyoxal and methylglyoxal) and co-products that are represented by conjugated $\gamma$-dicarbonyls (butenedial, 2-methylbutenedial and 4-oxo-2-pentenal) and furanones (2(5H)-furanone and $\beta$-angelicalactone). The epoxide route results in the formation of 2,3-epoxy-6-oxo-4-heptenal (in the following labelled epoxide-1) as the primary product. The first generation products of the ring-opening routes are gradually further oxidized resulting in higher oxygenated compounds with a declining number of carbon atoms, eventually producing $\mathrm{HCHO}, \mathrm{CO}$ and $\mathrm{CO}_{2}$. Owing to the limited experimental information available for these routes the implemented chemistry is a major area of uncertainty in the current mechanism.

The ring-opening pathways of the toluene oxidation proceed by a sequential addition of $\mathrm{OH}$ and $\mathrm{O}_{2}$ resulting in a hydroxycyclohexadienyl type peroxy radical (Fig. 1). Depending on the NO concentration there are three proposed reaction pathways for this radical: (1) a cyclisation to form a peroxide bridged radical which is the precursor for both the carbonyl and the epoxide route (Jenkin et al., 2002), (2) an isomerisation and subsequent release of $\mathrm{HO}_{2}$ to form cresol and (3) the reaction with NO resulting in the production of an oxy-radical that undergoes ring-opening and eventually results in the formation of muconaldehyde-type compounds. Ghigo and Tonachini (1999) and Motta et al. (2002) have investigated the photooxidation of benzene in theoretical studies. They both came to the conclusion that the NO promoted pathway can only compete with the cyclisation under polluted conditions. For NO concentrations of about $100 \mathrm{nmol} / \mathrm{mol}$ Ghigo and Tonachini (1999) estimate a branching ratio for the NO pathway of less than ten percent. Although this value was calculated for benzene, it can be taken as a tentative indication that the muconaldehyde route for aromatics in general is only of importance at $\mathrm{NO}_{\mathrm{x}}$ concentrations in the $\mu \mathrm{mol} / \mathrm{mol}$ range. This is in line with experimental studies at moderate $\mathrm{NO}_{\mathrm{x}}$ levels in which only qualitative evidence for muconaldehyde type compounds as minor reaction products in the toluene system was found (Yu et al., 1997). On the basis of the results of the theoretical studies and the weak experimental evidence for the muconaldehyde route in the toluene system this reaction pathway is not implemented in the MCM v3.

The three ring-retaining routes are labelled cresol, benzaldehyde and quinone. The cresol route has a significant effect on the $\mathrm{NO}_{\mathrm{x}}$ budget as it sequesters $\mathrm{NO}_{2}$ and $\mathrm{NO}_{3}$ into nitro-aromatics. Only $28 \%$ of cresol is further degraded by a ring-opening route to glyoxal and 4-oxopentenoic acid. The benzaldehyde and quinone routes are of only minor importance for toluene oxidation, due to their comparatively low yields. Benzaldehyde is the only first generation product that has no significant ring-opening channel, but, about $6 \%$ is further converted to nitrophenol by elimination of $\mathrm{CO}$. In the quinone route the oxidation of methyl-1,4-benzoquinone results in a variety of multioxygenates, which break down further to yield predominantly $\mathrm{CO}$ and $\mathrm{HCHO}$.

\section{Model experiment comparison}

\subsection{The smog-chamber experiment}

Owing to the complexity of the photooxidation of aromatics, only one-component experiments are suitable for the validation of aromatic mechanisms. The number of toluene- $\mathrm{NO}_{\mathrm{x}}$ experiments available is still very scarce. The experiment providing the most suitable dataset is the 22/10/97 toluene$\mathrm{NO}_{\mathrm{x}}$ system studied at the large-volume outdoor smogchamber EUPHORE, located in Valencia, Spain. The hemispherical chamber consists of FEP (fluorine ethene propene) foil and has a volume of $195.5 \mathrm{~m}^{3}$. The experiment was conducted as a classical smog-chamber run in which toluene $(482 \mathrm{nmol} / \mathrm{mol})$ and $\mathrm{NO}(134 \mathrm{nmol} / \mathrm{mol})$ were injected into the dark chamber. To start the reaction the protective housing was retracted so that the chamber was exposed to sunlight photoinitiating the toluene oxidation. The concentrations of toluene, $\mathrm{NO}, \mathrm{NO}_{2}$, and ozone were measured with a FTIR Spectrometer (Nicolet Magna 550) in combination with an open path white cell (optical path length, $526 \mathrm{~m}$ ). For the measurement of the photolysis rates of $\mathrm{O}_{3} \mathrm{NO}_{2}, \mathrm{HCHO}$ and HONO a spectroradiometer (Bentham DM300) was employed.

\subsection{The model simulation}

For the simulation of the 22/10/97 experiment the model was initialised with concentrations of toluene, $\mathrm{NO}, \mathrm{NO}_{2}$ and HONO. The high NO concentrations in the chamber at the point of $\mathrm{NO}$ injection led to production of $\mathrm{NO}_{2}$ by a termolecular reaction ( $2 \mathrm{NO}+\mathrm{O}_{2} \rightarrow 2 \mathrm{NO}_{2}$ ), giving an initial concentration of $\mathrm{NO}_{2}$ in the chamber of $14 \mathrm{nmol} / \mathrm{mol}$. Another side effect of the injection of NO into the chamber is the production of traces of $\mathrm{HONO}$, which is almost certainly generated from the reaction of the newly formed $\mathrm{NO}_{2}$ at the chamber wall (see discussion in Sect. 4.2). In the 22/10/97 experiment the initial HONO concentration was below the detection limit of the FTIR instrument of around $5 \mathrm{nmol} / \mathrm{mol}$. From earlier experiments in which HONO formation has been investigated, we know that the initial HONO concentration depends on the history of the chamber and the $\mathrm{NO}_{\mathrm{x}}$ loading. Based on information from those chamber characterisation studies we have estimated a HONO background 

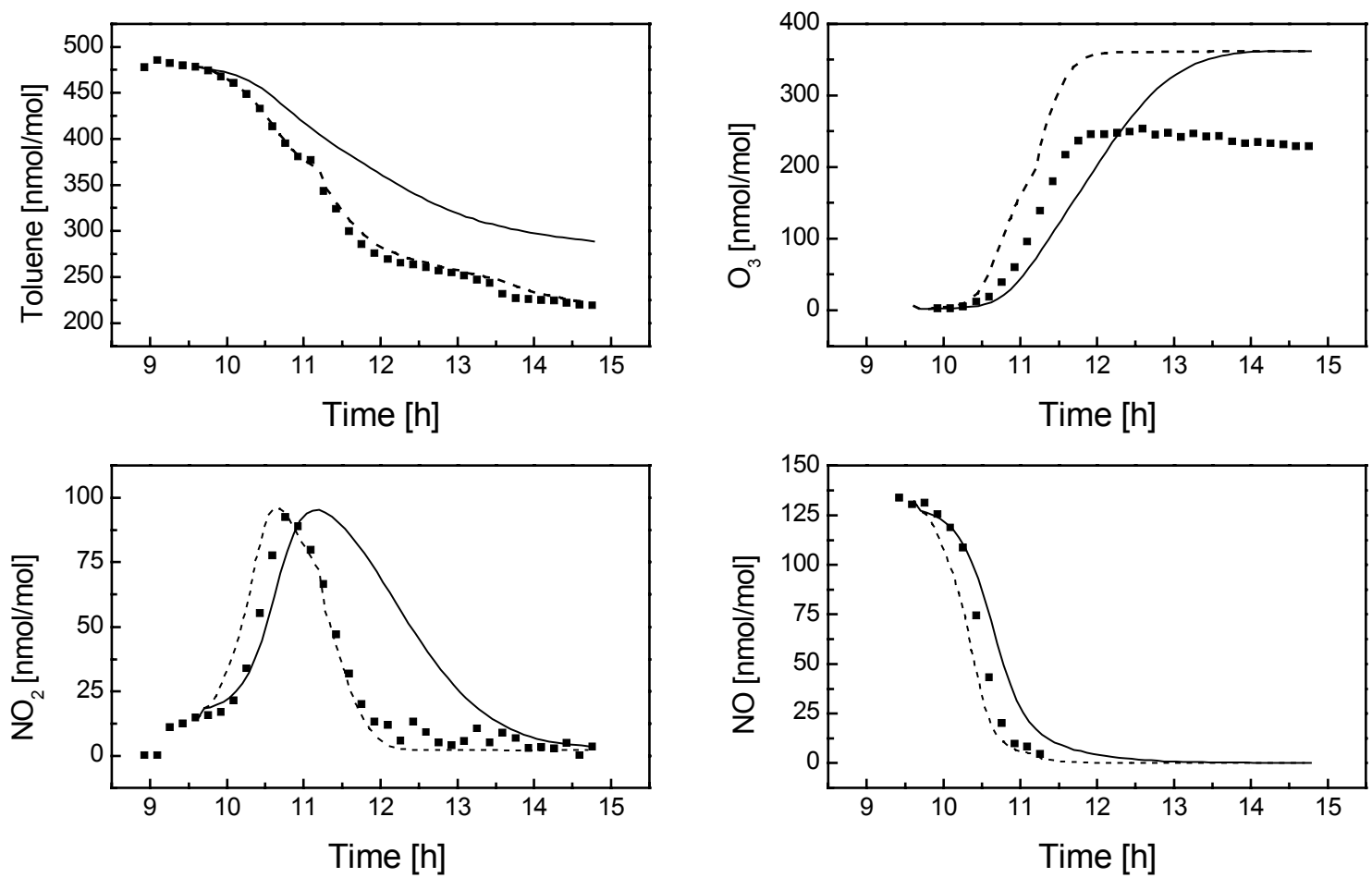

Fig. 3. Experimental and simulated concentration-time profiles for the toluene- $\mathrm{NO}_{\mathrm{x}}$ experiment 22/10/97 carried out at the EUPHORE chamber. Also shown, a model run in which an artificial $\mathrm{OH}$ source has been implemented in the model. The OH source strength has been tuned so that the modelled toluene decay matches the experimental values (see text).

concentration of $0.5 \mathrm{nmol} / \mathrm{mol}$ for the $22 / 10 / 97$ experiment and have initialised the model accordingly.

For $\mathrm{O}_{3}, \mathrm{NO}_{2}, \mathrm{HCHO}$ and $\mathrm{HONO}$ measured photolysis rates were taken for the model simulation. For all other photolysis processes, the corresponding boundary layer photolysis rates were calculated for the chamber location and experiment date, as described elsewhere (Saunders et al., 2002; Jenkin et al., 2002). These calculations do not consider the actual cloud coverage, the backscattering of the chamber floor and the transmission of the chamber FEP film. Therefore we have adjusted the calculated photolysis rates with a factor that is based on the average deviation between measured and calculated photolysis rates for $\mathrm{O}_{3}, \mathrm{NO}_{2}, \mathrm{HCHO}$ and HONO.

The results of the model-experiment comparison are shown in Fig. 3. The model predicts a toluene decay that is about $28 \%$ too low compared to the experiment, corresponding to a severe model under-prediction of the $\mathrm{OH}$ concentration (for all model experiment comparisons the experimental value is taken as $100 \%$ ). Despite the lower oxidation capacity, the model over-predicts the ozone concentration at the end of the experiment by about $55 \% . \mathrm{NO}_{2}$ concentrations are substantially higher than measured for the period after
$\mathrm{NO}_{2}$ has reached its maximum, in agreement with the model ozone over-prediction. The comparatively good agreement in the first $1.5 \mathrm{~h}$ indicates that in the early stages of the experiment, when the chemistry of the system is dominated by the initial oxidation step of toluene, the $\mathrm{NO}$ to $\mathrm{NO}_{2}$ conversion is well represented in the model. This conclusion is also supported by the good agreement between the experimental and simulated NO concentration-time-profile within the first hour. In the later stages of the experiment the oxidation of first and higher generation products becomes increasingly important. Shortcomings in the implemented chemistry of these compounds are probably responsible for the observed discrepancies in the $\mathrm{O}_{3}$ and $\mathrm{NO}_{2}$ concentration-time profiles.

\subsection{Product yields}

Mechanistic and observed product yields for first generation products in the toluene system are compiled in Table 1 . The cresol yields reported in 12 studies vary between $12 \%$ and $38.5 \%$ (Klotz et al., 1998, and references therein). In the model only one surrogate compound is implemented that represents all three isomers of cresol. The mechanistic yield of $20 \%$ for this compound comes close to experimental values 
Table 1. First generation product yields in the toluene system: comparison between model and literature data

\begin{tabular}{|c|c|c|c|}
\hline \multirow[b]{2}{*}{ Intermediate } & \multicolumn{2}{|c|}{ Yield $(\%)$} & \multirow[b]{2}{*}{ Reference } \\
\hline & Model & Literature & \\
\hline o-Cresol & 20.0 & $12-38.5$ & [7] \\
\hline $\mathrm{m}-+\mathrm{p}-\mathrm{Cresol}$ & - & $4.8-5.9$ & {$[4,7]$} \\
\hline Benzaldehyde & 6.0 & $5.4-12$ & {$[4,7]$} \\
\hline Glyoxal & 23.8 & $8-39$ & {$[4,5]$} \\
\hline Methylglyoxal & 23.8 & $7.5-16.7$ & {$[2,4]$} \\
\hline Butenedial & 11.9 & Detected & {$[1,2]$} \\
\hline 4-Oxo-2-pentenal & 7.9 & 3.1 & [2] \\
\hline 2-Methylbutenedial & 7.9 & Detected & [8] \\
\hline 2(5H)-Furanone & 11.9 & Proposed & {$[3]$} \\
\hline$\alpha$-Angelicalactone ${ }^{\mathrm{a}}$ & 7.9 & 2.9 & {$[2]$} \\
\hline 2,3-Epoxy-6-oxo-heptenal & 20.0 & Evidence & {$[6]$} \\
\hline Methyl-1,4-benzoquinone & 4.6 & Detected & [1] \\
\hline
\end{tabular}

${ }^{a}$ In the model represented as $\beta$-angelicalactone.

References are as follows: [1] Yu et al., 1997; [2] Smith et al., 1998; [3] this work; [4] Atkinson, 1992; [5] Volkamer et al., 2001, and references therein; [6] Yu and Jeffries, 1997; [7] Klotz et al., 1998, and references therein; [8] Jang and Kamens, 2001.

published more recently by Klotz et al. (1998) and Smith et al. (1998). For benzaldehyde, the spread in literature yields is a factor of two and the model gives a yield of $6 \%$ that is supported by several studies published in the nineties by Klotz et al. (1998), Bierbach et al. (1994), and Seuwen and Warneck (1996). Literature values for the glyoxal yield vary between 8\% and 39\% (Atkinson, 1992; Volkamer et al., 2001 and references therein). This spread of more than a factor of four indicates high experimental uncertainties. In the model only the dicarbonyl route, with a branching ratio of $48 \%$, yields glyoxal and methylglyoxal as first generation products. According to the different possible symmetries of the peroxidebicyclic intermediate, and the different positions where the ring of this radical can break, there are 5 ring-opening routes implemented in the model. They result either in the formation of glyoxal and a $\mathrm{C}_{5}$ co-product or methylglyoxal and a $\mathrm{C}_{4}$ co-product. The branching ratios for the $\mathrm{C}_{4}$ and $\mathrm{C}_{5}$ pathways is set to $50 \%$ giving yields of $23.8 \%$ for both, glyoxal and methylglyoxal. The yields most recently published are higher for glyoxal but lower for methylglyoxal with 39\% and $16.7 \%$ respectively (Volkamer et al., 2001; Smith et al., 1998). This indicates that the glyoxal route is the favoured ring-opening pathway and the combined branching ratio of the two routes might be some percent higher than currently implemented in the model. However, the uncertainties in the measured yields are still very high, and they should be confirmed by further studies before the mechanism is adjusted accordingly.

The co-products of glyoxal and methylglyoxal are represented in the model by three $\gamma$-dicarbonyls, butenedial, 2-methylbutenedial, 4-oxo-2-pentenal, and two furanones, $2(5 \mathrm{H})$-furanone and $\alpha$-angelicalactone. They result from applying a set of rules, based on structure activity relations, to the breakdown of possible isomers of the peroxide-bicyclic intermediate. Only two of the co-products, $\alpha$-angelicalactone and 4-oxo-2-pentenal, could be quantified in laboratory experiments (Smith et al., 1998), while qualitative evidence exists for two further co-products, butenedial and 2-methylbutenedial (Yu et al., 1997; Smith et al., 1998; Jang and Kamens, 2001). 2(5H)-furanone has only been proposed and not observed (this work). If we assume a glyoxal yield of $39 \%$, as suggested by measurements of Volkamer et al. (2001), only $15 \%$ of the possible co-products could be quantified in laboratory experiments (Smith et al., 1998). The poor carbon balance shows that the degradation chemistry of the dicarbonyl route is still a major area of uncertainty in the understanding of toluene oxidation chemistry. The most speculative reaction channel is the epoxide pathway, currently implemented with a yield of $20 \%$. For this reaction channel and putative oxidation products only qualitative evidence could be found so far (Yu and Jeffries, 1997).

\section{The radical budget}

\subsection{Procedure}

The hydroxyl radical, as dominant oxidant, defines the oxidation capacity in the toluene system. Thus, the net effect of an intermediate on the $\mathrm{OH}$ radical budget is a reliable measure for its contribution to the oxidation capacity of the system. However, $\mathrm{OH}$ is in a quasi steady state so that, while its production and sink terms are of the order of $10^{-2} \mathrm{nmol} / \mathrm{mol}$ $\mathrm{s}^{-1}$, the net $\mathrm{OH}$ production is only around $10^{-7} \mathrm{nmol} / \mathrm{mol}$ $\mathrm{s}^{-1}$. A calculation of the net production by taking the difference between sink and production terms at short time scales is thus beyond the precision of the numerical integration process. However, the production of new radicals is the key process feeding the radical chain and maintaining high radical levels in the system, in competition with the radical sink processes, such as reaction of $\mathrm{OH}$ with $\mathrm{NO}_{2}$ and peroxy-peroxy radical termination. For this reason, new radicals produced by a compound or a reaction channel provide a good measure of its effect on the overall oxidation capacity of a reaction system.

The photooxidation of a generic VOC involves the following radical transformation sequence (e.g. Jenkin and Clemitshaw, 2000): the oxidation is initiated by reaction of $\mathrm{OH}$ with the VOC; the net effect is a conversion of $\mathrm{OH}$ into $\mathrm{RO}_{2}$ (see also Fig. 4). $\mathrm{RO}_{2}$ propagates by reaction with $\mathrm{NO}$ to $\mathrm{RO}$, which in turn reacts with oxygen to produce $\mathrm{HO}_{2}$ and a carbonyl compound. The cycle is closed by the conversion of 


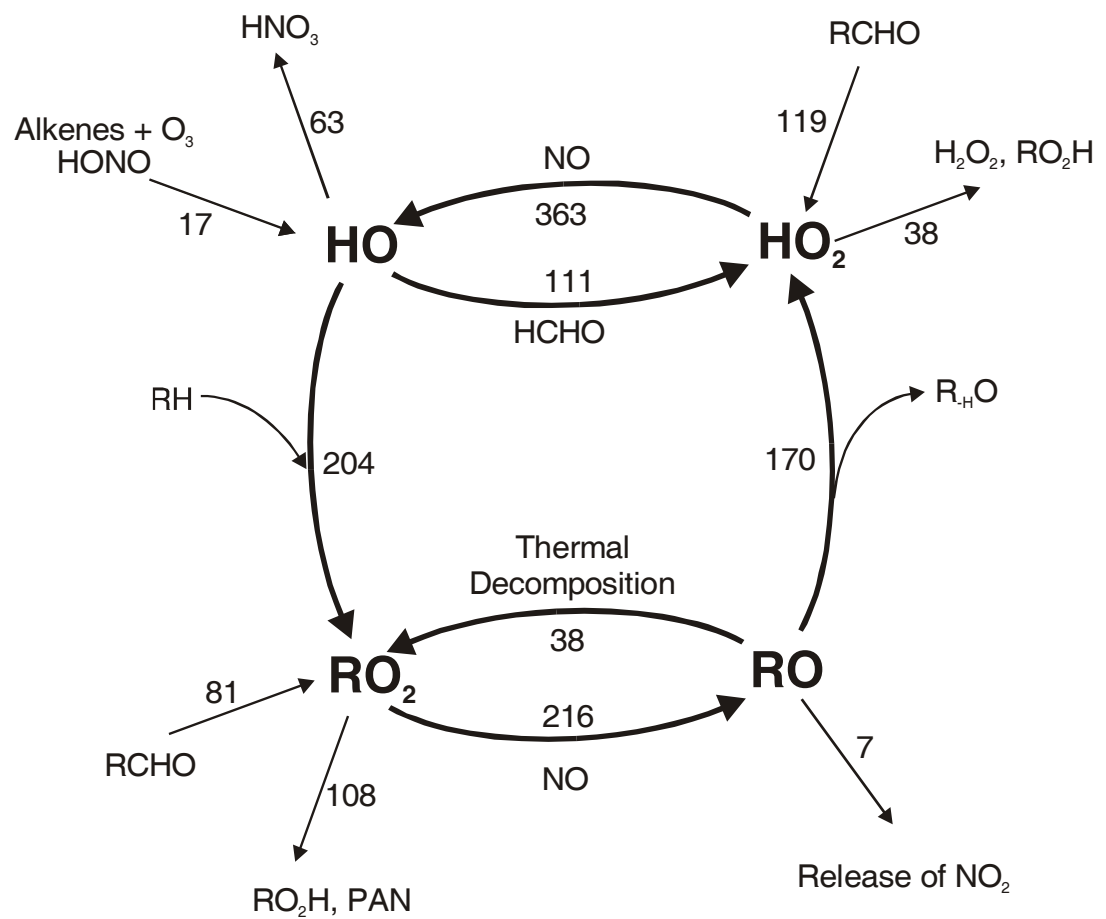

Fig. 4. Schematic representation of the $\mathrm{RO}_{\mathrm{x}}$ cycle in the toluene system, showing major routes of transformation between $\mathrm{OH}, \mathrm{RO}_{2}, \mathrm{RO}$ and $\mathrm{HO}_{2}$ radicals and source and sink processes for each $\mathrm{RO}_{\mathrm{x}}$ species. The numbers are total flows through the transformation channels in units of $\mathrm{nmol} / \mathrm{mol}$ calculated for the entire time of the toluene- $\mathrm{NO}_{\mathrm{x}}$ experiment 22/10/97.
$\mathrm{HO}_{2}$ back into $\mathrm{OH}$ by reaction with NO. Major sources of $\mathrm{RO}_{\mathrm{x}}$ radicals are the photolysis of aldehydes and the reaction of $\mathrm{O}_{3}$ with alkenes. Radicals are removed from the reaction system by termination processes such as reaction of $\mathrm{OH}$ with $\mathrm{NO}_{2}$ and peroxy-peroxy radical termination. Based on this fundamental description of the radical transformation in photochemical systems we have calculated the $\mathrm{RO}_{\mathrm{x}}$ budget for the 22/10/97 toluene experiment. We applied the following definitions and procedures, which enabled us to consider all radical conversion processes in the toluene mechanism:

1. New radical production is defined as breakdown of a closed shell molecule into two radical species or a transformation of $\mathrm{NO}_{3}$ into a $\mathrm{RO}_{\mathrm{x}}$ species. As stated above, the most abundant processes of new radical production are photolysis of carbonyls and ozonolysis of alkenes. Furthermore the reaction of $\mathrm{NO}_{3}$ with VOC produces $\mathrm{RO}_{\mathrm{x}}$ radicals and thus acts as a link between the $\mathrm{NO}_{\mathrm{x}}$ and $\mathrm{RO}_{\mathrm{x}}$ radical families. $\mathrm{RO}_{2}$ production through reactions such as $\mathrm{RH}+\mathrm{NO}_{3}+\mathrm{O}_{2} \rightarrow \mathrm{RO}_{2}+\mathrm{HNO}_{3}$ is also classified as new radical production.

2. Propagation is the transformation of one $\mathrm{RO}_{\mathrm{x}}$ species into another $\mathrm{RO}_{\mathrm{x}}$ species.

3. Termination is defined as combination of two radicals to form a closed shell molecule.

4. For compounds that are in a fast equilibrium with radicals, net terms are calculated. For example, the thermal decomposition of PAN-type compounds is not taken as radical production, but subtracted from the $\mathrm{RC}(\mathrm{O}) \mathrm{O}_{2}+$ $\mathrm{NO}_{2}$ consumption term.

5. Compounds that are produced by radical radical combination and that then break down into radicals of another type (e.g. hydroperoxides) are defined as temporary reservoirs and their breakdown is taken into account as "delayed" radical propagation. These processes account for less than $1 \%$ of the major radical propagation routes under conditions of the 22/10/97 experiment. Therefore they are not treated separately, but added to the major radical conversion routes, according to the net effect the delayed radical propagation has on the $\mathrm{RO}_{\mathrm{x}}$ budget.

$\mathrm{RO}_{2}$ and $\mathrm{HO}_{2}$ account for a large fraction of the newly produced radicals in the reaction system, but only the portion of them that is converted into $\mathrm{OH}$ contributes to the oxidation capacity of the system. For this reason we define $\mathrm{OH}$ equivalents as the fraction of $\mathrm{HO}_{2}$ or $\mathrm{RO}_{2}$ that is effectively transformed into $\mathrm{OH}$ :

$[\mathrm{OHeq}]_{\mathrm{HO}_{2}}=\gamma_{\mathrm{HO}_{2}} \cdot\left[\mathrm{HO}_{2}\right]$,

$[\mathrm{OHeq}]_{\mathrm{RO}_{2}}=\gamma_{\mathrm{RO}_{2}} \cdot\left[\mathrm{RO}_{2}\right]$,

where $\gamma_{\mathrm{HO}_{2}}$ and $\gamma_{\mathrm{RO}_{2}}$ represent the conversion factors from one radical species into $\mathrm{OH}$ :

$$
\begin{aligned}
\gamma_{\mathrm{HO}_{2}} & =\frac{\mathrm{HO}_{2} \text { conversion to } \mathrm{OH}}{\text { total } \mathrm{HO}_{2} \text { consumption }}, \\
\gamma_{\mathrm{RO}_{2}} & =\gamma_{\mathrm{HO}_{2}} \frac{\mathrm{RO}_{2} \text { conversion to } \mathrm{HO}_{2}}{\text { total } \mathrm{RO}_{2} \text { consumption }} .
\end{aligned}
$$




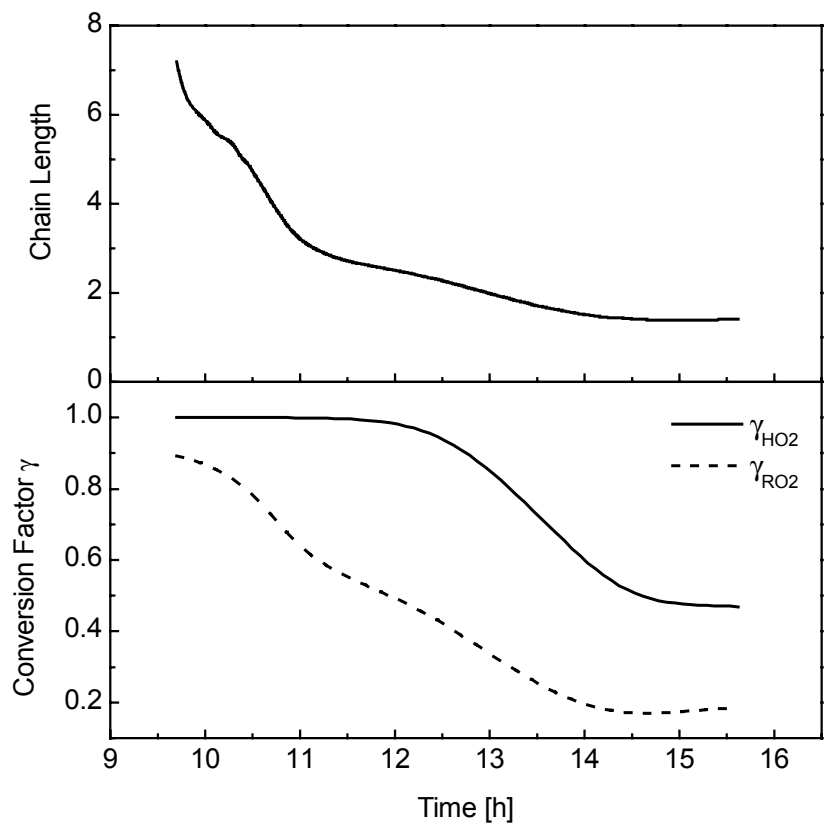

Fig. 5. Time profiles for chain length and conversion factors $\gamma$ calculated for the toluene- $\mathrm{NO}_{\mathrm{x}}$ experiment 22/10/97. The conversion factor $\gamma$ is defined as the fraction of a radical species $\left(\mathrm{RO}_{2}\right.$ or $\left.\mathrm{HO}_{2}\right)$ that is converted into $\mathrm{OH}$.

Total new $\mathrm{OH}\left(\Sigma \mathrm{OH}_{\text {new }}\right)$ is then defined as the sum of new $\mathrm{OH}$ and $\mathrm{OH}$ equivalents from new $\mathrm{HO}_{2}$ ([new $\left.\mathrm{OHeq}\right]_{\mathrm{HO}_{2}}$ ) and new $\mathrm{RO}_{2}$ ([new $\mathrm{OHeq}_{\mathrm{RO}_{2}}$ ):

$$
\begin{aligned}
& \Sigma \mathrm{OH}_{\text {new }}=[\text { new OH }]+[\text { new OHeq }]_{\mathrm{HO}_{2}} \\
& \quad+[\text { new OHeq }]_{\mathrm{RO}_{2}} .
\end{aligned}
$$

With this definition we can finally calculate the effective chain length of the radical cycle in the toluene system, which is the average number of times a newly created $\mathrm{OH}$ radical will be recreated through radical chain propagation before it is destroyed:

$\mathrm{n}(\mathrm{OH})=\frac{\Sigma \mathrm{OH}_{\text {new }}+\text { propagated } \mathrm{OH}}{\Sigma \mathrm{OH}_{\text {new }}}$.

The $\mathrm{OH}$ chain length is an important parameter for smogchamber experiments that gives information about the relative importance of radical production to the total radical turnover in the system.

Classification of all reactions and subsequent calculation of the $\mathrm{RO}_{\mathrm{x}}$ budget for the toluene system is a prerequisite to compute the conversion factors for $\mathrm{HO}_{2}$ and $\mathrm{RO}_{2}$ into $\mathrm{OH}$ and hence, the contribution of a compound or reaction channel to $\Sigma \mathrm{OH}_{\text {new }}$. These calculations enable us to identify the compounds and reaction channels that dominate the oxidation capacity of the system and which are most likely to be responsible for the current shortcomings in the toluene mechanism.

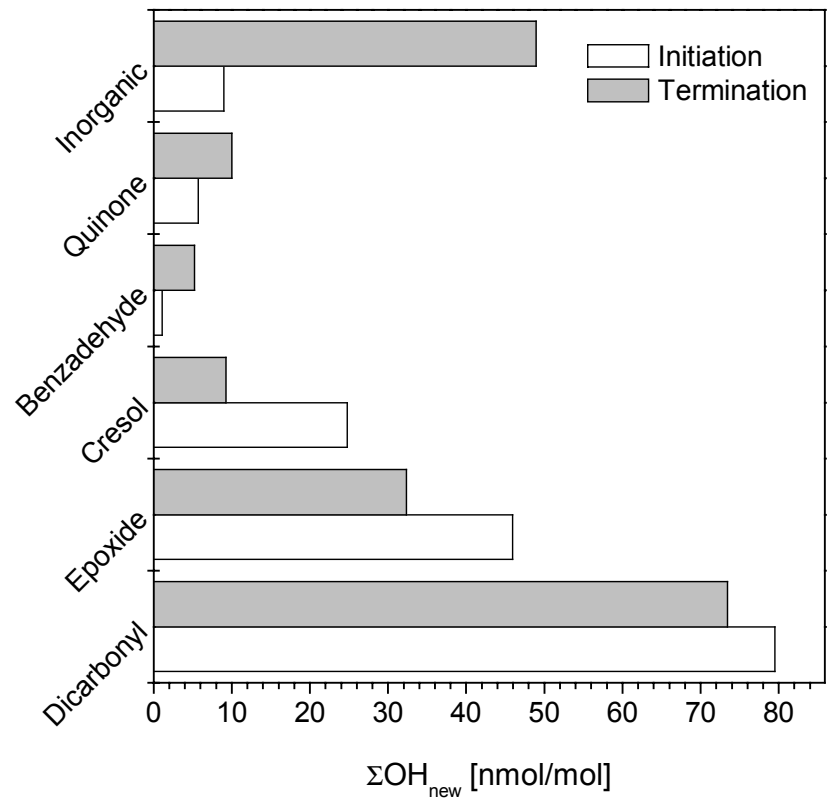

Fig. 6. Total new $\mathrm{OH}\left(\Sigma \mathrm{OH}_{\text {new }}\right)$ production and termination in reaction channels of the toluene system, calculated over the course of the 22/10/97 experiment. Initiation and termination of $\mathrm{HO}_{2}, \mathrm{RO}_{2}$ is considered in terms of $\mathrm{OH}$ equivalents (see text).

\subsection{The $\mathrm{OH}$ budget}

The calculated radical fluxes in the toluene- $\mathrm{NO}_{\mathrm{x}}$ system 22/10/97 are shown in Fig. 4. They are given as amount of radicals, in units of $\mathrm{nmol} / \mathrm{mol}$, that follow each pathway over the entire time of the simulation. New $\mathrm{OH}$ production is about $17 \mathrm{nmol} / \mathrm{mol}$ from ozonolysis of alkenes and photolysis of $\mathrm{HONO}$ that is formed by reaction of $\mathrm{NO}_{2}$ on the chamber walls. $119 \mathrm{nmol} / \mathrm{mol}$ of new $\mathrm{HO}_{2}$ is produced, mainly by the photolysis of aldehydes, and $81 \mathrm{nmol} / \mathrm{mol} \mathrm{RO}_{2}$ is created, with photolysis of aldehydes and ozonolysis of alkenes as major sources. $63 \mathrm{nmol} / \mathrm{mol}$ of $\mathrm{OH}$ is directly lost via reaction with $\mathrm{NO}_{2}$ and PAN-type compounds and a further $153 \mathrm{nmol} / \mathrm{mol}$ of $\mathrm{RO}_{\mathrm{x}}$ is lost by various sink reactions, such as formation of hydroperoxides, peroxy-peroxy permutation reactions and formation of nitrates. Applying the transformation factors, we calculate a $\Sigma \mathrm{OH}_{\text {new }}$ production of $162 \mathrm{nmol} / \mathrm{mol}$ over the course of the experiment, with a contribution of new $\mathrm{OH}$ equivalents from $\mathrm{HO}_{2}$ and $\mathrm{RO}_{2}$ of $107 \mathrm{nmol} / \mathrm{mol}$ and $38 \mathrm{nmol} / \mathrm{mol}$, respectively. The calculations were carried out as a function of time to investigate the time dependencies of the chain length and conversion factors. At the beginning of the experiment the chain length is 7.2 and the conversion factors $\gamma \mathrm{HO}_{2}$ and $\gamma \mathrm{RO}_{2}$ are 1 and 0.9 , respectively (Fig. 5). The high NO concentration allows radical propagation to dominate sink processes and the radicals cycle several times between the different radical types before they are destroyed by termination reactions. As [NO] decreases and $\left[\mathrm{RO}_{\mathrm{x}}\right]$ increases, $\mathrm{HO}_{2}$ and $\mathrm{RO}_{2}$ combination 
Table 2. Total new $\mathrm{OH}\left(\Sigma \mathrm{OH}_{\text {new }}\right)$ and $\mathrm{NO}$ to $\mathrm{NO}_{2}$ conversion in reaction channels of the toluene system, calculated for the toluene- $\mathrm{NO}_{\mathrm{x}}$ experiment 22/10/97

\begin{tabular}{|c|c|c|c|c|c|}
\hline \multirow[b]{2}{*}{$\begin{array}{l}\text { Reaction } \\
\text { channel }\end{array}$} & \multirow[b]{2}{*}{$\begin{array}{l}\text { Branching } \\
\text { ratio }\end{array}$} & \multicolumn{3}{|c|}{ Per molecule toluene oxidized } & \multirow{2}{*}{$\begin{array}{c}\begin{array}{c}\text { Per molecule } \\
\mathrm{NO}_{2} \text { consumed }\end{array} \\
\mathrm{NO} \text { to } \mathrm{NO}_{2} \\
\text { conversion }\end{array}$} \\
\hline & & $\begin{array}{c}\text { Total new } \\
\text { OH }\end{array}$ & $\begin{array}{l}\mathrm{NO} \text { to } \mathrm{NO}_{2} \\
\text { conversion }\end{array}$ & $\begin{array}{c}\mathrm{NO}_{\mathrm{x}} \\
\text { consumed }\end{array}$ & \\
\hline Dicarbonyl & 0.48 & 1.1 & 4.7 & 0.69 & 6.8 \\
\hline Epoxide & 0.2 & 1.5 & 4.9 & 0.90 & 5.5 \\
\hline Cresol & 0.2 & 0.7 & 2.4 & 0.88 & 2.8 \\
\hline Benzaldehyde & 0.07 & 0.1 & 1.3 & 0.41 & 3.1 \\
\hline Quinone & 0.05 & 0.7 & 3.7 & 0.65 & 5.8 \\
\hline
\end{tabular}

processes become more important and the chain length continuously decreases over the course of the experiment. By the end of the experiment, [NO] has dropped to $0.1 \mathrm{nmol} / \mathrm{mol}$ resulting in a chain length of 1.4 and conversion factors for $\mathrm{HO}_{2}$ and $\mathrm{RO}_{2}$ of 0.48 and 0.17 , respectively.

To assess the importance of the major reaction channels to the oxidation capacity we calculated $\Sigma \mathrm{OH}_{\text {new }}$ production and consumption separately for each of them. The results show that the dicarbonyl, epoxide and cresol routes act as radical donors in the system as their radical production terms are higher than their sink terms (Fig. 6). The benzaldehyde, the quinone route and the inorganic chemistry (mainly the reaction of $\mathrm{NO}_{2}+\mathrm{OH}$ ) have sink terms that are higher than their production terms. The largest contribution to the total new $\mathrm{OH}$ production comes from the dicarbonyl route with $80 \mathrm{nmol} / \mathrm{mol} \Sigma \mathrm{OH}_{\text {new }}$. Table 2 shows the number of $\Sigma \mathrm{OH}_{\text {new }}$ radicals produced per toluene molecule oxidized for each channel. The dicarbonyl and the epoxide routes are most efficient in producing $\Sigma \mathrm{OH}_{\text {new }}$ as they break down into a number of carbonyl compounds, which photolyse and produce radicals in high yields. The quinone and cresol routes have a lower efficiency in producing radicals as in the first generation products the aromatic ring is retained. Thus, ring-opening occurs a reaction sequence later and the ringopening products are more oxidized and show less propensity to produce radicals. The benzaldehyde route has no significant ring-opening channel and the net radical production of the photolysis of benzaldehyde is relatively low as the corresponding acyl peroxy radical sequesters $\mathrm{NO}_{\mathrm{x}}$ efficiently by forming peroxybenzoyl nitrate. Through removing $\mathrm{NO}_{\mathrm{x}}$ the chain length is decreased, which compensates to a large extent the new radical production by the initial photolysis of benzaldehyde. Apparently, ring-opening is a prerequisite for a strong radical production in a reaction pathway, as ringretaining oxidation processes do not provide enough aldehydes, which act as efficient radical sources.

Table 3 shows the 11 most important radical sources in the toluene system that produce about $80 \%$ of $\Sigma \mathrm{OH}_{\text {new }}$. Apart from $\mathrm{HCHO}$, all compounds are solely or predominantly formed in first generation processes. Owing to a combination of a high yield and high photolysis rates, methylglyoxal is the strongest radical source followed by epoxide- 1 and glyoxal. Furthermore, the conjugated $\gamma$-dicarbonyls (4-oxo-2pentenal, butenedial, and 2-methylbutenedial) and furanones ( $2(5 \mathrm{H})$-furanone and $\alpha$-angelicalactone), which represent the co-products of glyoxal and methylglyoxal, are also of major importance, contributing $25 \%$ to $\Sigma \mathrm{OH}_{\text {new }}$. The photolysis of $\mathrm{HONO}$, which is produced by wall reactions of $\mathrm{NO}_{2}$, accounts for $9 \mathrm{nmol} / \mathrm{mol}$ of the newly produced $\mathrm{OH}$ over the course of the experiment.

The analysis of the radical budget also gives information on the importance of chamber effects for the radical turnover in a toluene experiment. Based on characterisation measurements at the EUPHORE chamber the radical production caused by wall reactions can be described by a process in which gas-phase $\mathrm{NO}_{2}$ is transformed into HONO. Thus, the rate of HONO production on the walls is a function of the $\mathrm{NO}_{2}$ concentration in the chamber. For this process $\left(\mathrm{NO}_{2} \rightarrow \mathrm{HONO}\right)$ an average rate coefficient $\mathrm{k}_{\mathrm{HONO}}$, wall of $(1.15 \pm 0.45) \times 10^{-5} \mathrm{~s}^{-1}$ has been established for the EUPHORE chamber. Unfortunately HONO formation is not a constant but also depends on the history of the chamber, so that the actual source strength of HONO production for a particular experiment is not known. However, the average value for $\mathrm{k}_{\mathrm{HONO}}$,wall gives a good first guess for wall production of HONO and was used in the simulations of the 22/10/97 experiment.

Over the whole course of the 22/10/97 experiment the total $\mathrm{OH}$ production by the photolysis of HONO resulting from wall reactions is only $9 \mathrm{nmol} / \mathrm{mol}$ compared to a $\Sigma \mathrm{OH}_{\text {new }}$ production in the toluene system of $153 \mathrm{nmol} / \mathrm{mol}$. Even if we double the rate constant for the conversion of $\mathrm{NO}_{2}$ to $\mathrm{HONO}, \mathrm{OH}$ production by chamber effects would be only of the order of $12 \%$ of the $\Sigma \mathrm{OH}_{\text {new }}$ production of the toluene system.

For conditions such as those in the 22/10/97 experiment the effect of wall produced radicals on the $\mathrm{OH}$ production in the early and middle stages of the experiment is certainly 
Table 3. Total new $\mathrm{OH}\left(\Sigma \mathrm{OH}_{\text {new }}\right)$ production by compounds over the course of an experiment. Calculated for the toluene- $\mathrm{NO}_{\mathrm{x}}$ experiment 22/10/97

\begin{tabular}{lcc}
\hline Compound & $\begin{array}{c}\Sigma \mathrm{OH}_{\text {new }} \\
(\mathrm{nmol} / \mathrm{mol})\end{array}$ & $\begin{array}{c}\text { Contribution to } \\
\Sigma \mathrm{OH}_{\text {new }} \text { in toluene } \\
\text { system }(\%)\end{array}$ \\
\hline Methylglyoxal & 24.4 & 15.1 \\
Epoxide-1 & 24.1 & 14.9 \\
Glyoxal & 14.9 & 9.2 \\
4-Oxo-2-pentenal & 12.6 & 7.8 \\
Butenedial & 10.4 & 6.4 \\
Cresol & 8.7 & 5.4 \\
HONO & 8.4 & 5.2 \\
HCHO & 7.6 & 4.7 \\
$\alpha-$ Angelicalactone & 7.6 & 4.7 \\
2-Methylbutenedial & 5.2 & 3.2 \\
2(5H)-Benzofuranone & 5.1 & $\underline{3.2}$ \\
Sum & & 79.8 \\
\hline
\end{tabular}

minor and cannot explain the model-experiment discrepancies in the $\mathrm{OH}$ production and the toluene decay. However, as over the course of an experiment a complex mixture of highly reactive organics and $\mathrm{NO}_{\mathrm{y}}$ species are transferred to the walls, at the end of an experiment (final $1.5 \mathrm{~h}$ ) the situation becomes more uncertain. There might be a variety of wall related processes producing radicals, which so far have not been considered. Therefore, it cannot be ruled out that at the end of an experiment chamber effects have indeed a significant impact on the radical production in the system.

\subsection{Time profiles of new $\mathrm{OH}$ production}

To quantify the missing $\mathrm{OH}$ production in the model we implemented an artificial $\mathrm{OH}$ source and tuned the source rate so that exactly the amount of $\mathrm{OH}$ is injected into the system that is needed to match the measured toluene decay. From this procedure we showed that an additional $300 \mathrm{nmol} / \mathrm{mol}$ $\mathrm{OH}$ is necessary over the course of an experiment to bring the simulated and experimental toluene decays into agreement. This means that the modelled $\mathrm{OH}$ production of $380 \mathrm{nmol} / \mathrm{mol}$ (see also Fig. 4) is around $44 \%$ too low compared to the experiment.

A more detailed picture of the nature of the missing $\mathrm{OH}$ source can be derived from the time dependencies of $\mathrm{OH}$ sources in the system. If we consider the discrepancies from a model point of view it becomes clearer how much the $\mathrm{OH}$ production in the model has to be increase to match the radical production in the experiment. The time profiles in Fig. 7 show that, at all times during the experiment, $\Sigma \mathrm{OH}_{\text {new }}$ production in the model is too low by at least $25 \%$ (model OH

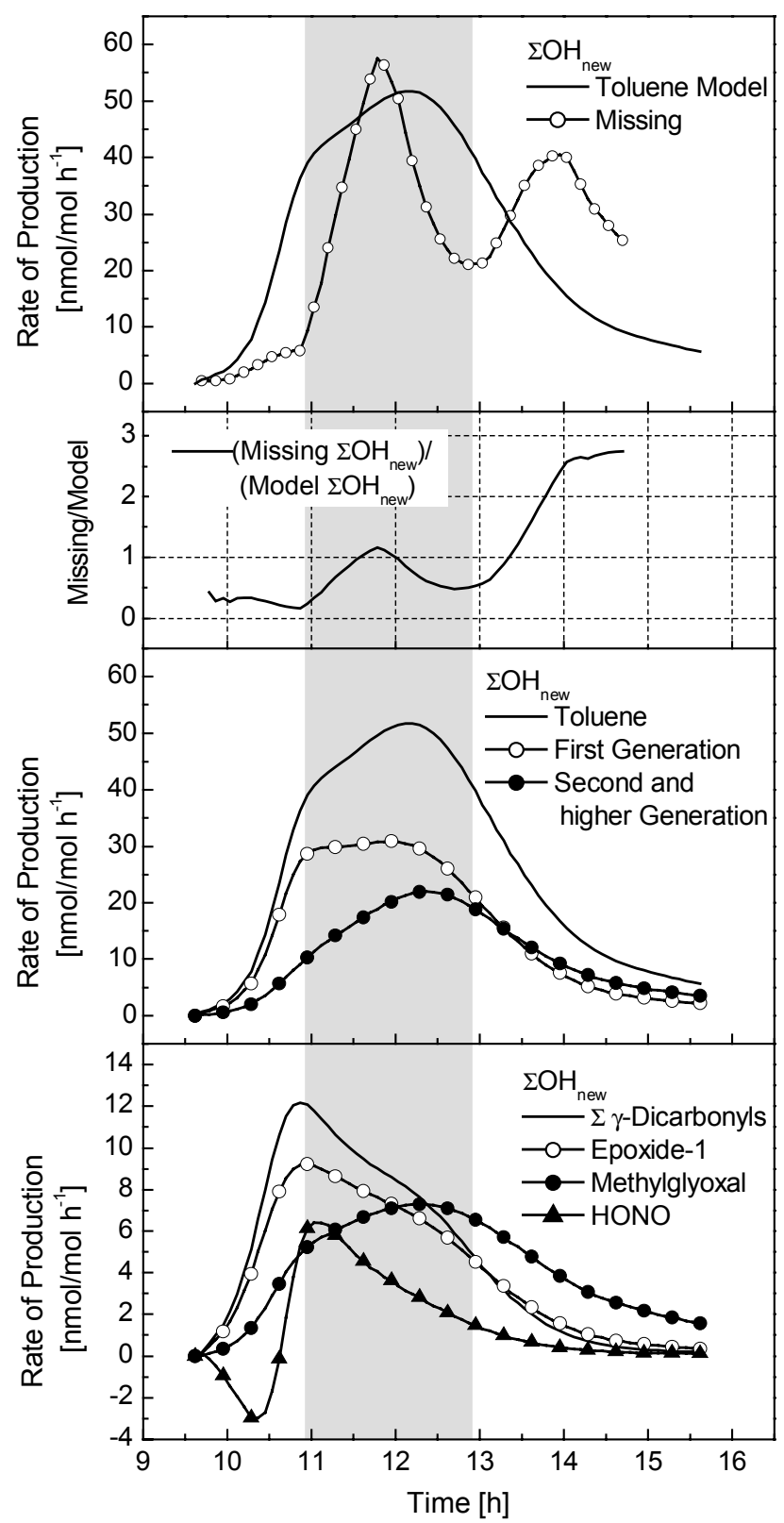

Fig. 7. Time profiles for $\mathrm{OH}$ production: (1) Modelled total new $\mathrm{OH}$ $\left(\Sigma \mathrm{OH}_{\text {new }}\right)$ production in the toluene system and missing $\Sigma \mathrm{OH}_{\text {new }}$. (2) Missing $\Sigma \mathrm{OH}_{\text {new }}$ as fraction of modelled $\Sigma \mathrm{OH}_{\text {new }}$. (3) Contributions of first and second generation products to $\Sigma \mathrm{OH}_{\text {new }}$. (4) $\Sigma \mathrm{OH}_{\text {new }}$ produced by strongest radical sources in the reaction system. Grey area indicates the time period when the missing $\mathrm{OH}$ shows a distinct maximum suggesting a strong radical source that is not yet implemented in the model.

is taken as $100 \%)$. Around 12:00 the $\Sigma \mathrm{OH}_{\text {new }}$ production in the experiment is about a factor of two higher than in the model and in the final 1.5 hours of the experiment the deviation increases to about a factor of three. Panel 3 of Fig. 7 shows that, in the model, first generation products dominate $\Sigma \mathrm{OH}_{\text {new }}$ production until about 12:00. In the latter stages of 
the experiment second generation products gain more importance, making up about $60 \%$ of $\Sigma \mathrm{OH}_{\text {new }}$.

The time profiles of $\Sigma \mathrm{OH}_{\text {new }}$ production differ significantly depending on the photo-chemical reactivity of a compound (Fig. 7, panel 4). The photolysis of small amounts of "background" HONO (an estimated $0.5 \mathrm{nmol} / \mathrm{mol}$ ), produced during the injection of NO into the chamber, initiates the photochemistry in the toluene- $\mathrm{NO}_{\mathrm{x}}$ system. Once initial $\mathrm{HONO}$ is photolysed the recombination reaction of $\mathrm{NO}$ with $\mathrm{OH}$ to $\mathrm{HONO}$ becomes a net sink for $\mathrm{OH}$. After one hour of reaction time, when significant amounts of NO have beenconverted into $\mathrm{NO}_{2}$ so that HONO formation on the walls increases and $\mathrm{OH}$ loss via reaction with $\mathrm{NO}$ becomes less important, HONO is again a net source of radicals. An important result of the $\mathrm{OH}$ production analysis is that conjugated $\gamma$-dicarbonyls and epoxide- 1 are essential for $\mathrm{OH}$ production in the early stages of the experiment. Methylglyoxal and glyoxal, both first generation products, are strong radical sources in the system but the radical production rate is initially too slow to explain the high $\mathrm{OH}$ concentration at the beginning of the experiment.

From the analysis of the time profiles of $\Sigma \mathrm{OH}_{\text {new }}$ production we can conclude that a general increase of the "background" production rate for $\Sigma \mathrm{OH}_{\text {new }}$ of about $25 \%$ in the model is necessary to describe the oxidation capacity in the experiment. At 12:00, when $[\mathrm{OH}]$ in the system peaks, a distinctive increase of the radical production in the model is necessary. An increase in the photolysis rates of conjugated $\gamma$-dicarbonyls or epoxide- 1 to reproduce this $\mathrm{OH}$ peak would necessarily lead to an overestimation of the reactivity at the beginning of the experiment, whereas an increase in the $\Sigma \mathrm{OH}_{\text {new }}$ production rate of second and higher generation products would produce an $\mathrm{OH}$ peak that is too late. The analysis of the time profiles suggests a strong radical source that is not yet implemented in the mechanism and that produces new radicals in a period between the peaks of the $\Sigma \mathrm{OH}_{\text {new }}$ production rates corresponding to the photochemistry of first and second/higher generation products. As pointed out above, the nature and the photochemical fate of the co-products of glyoxal and methylglyoxal and the intermediates in the epoxide route are a major area of uncertainty in the toluene mechanism. Hence, it is very likely that these parts of the mechanism are responsible for the observed discrepancies between modelled and experimental $\mathrm{OH}$ production in the early and middle stages of the experiment.

In the last two hours of the experiment the modelled $\mathrm{OH}$ production is too low by $55 \mathrm{nmol} / \mathrm{mol}$. Because of low [NO] at the end of the experiment, the conversion factors for $\mathrm{HO}_{2}$ and $\mathrm{RO}_{2}$ are less than 0.5 and the rate of production of new radicals in the system has to be more than tripled to explain the measured toluene decay. This points to a severe lack of understanding of the chemistry in the latter stages of the experiment, when reaction products of the toluene oxidation become increasingly important as reaction partners for $\mathrm{OH}$. The situation becomes even more intricate as the effect of

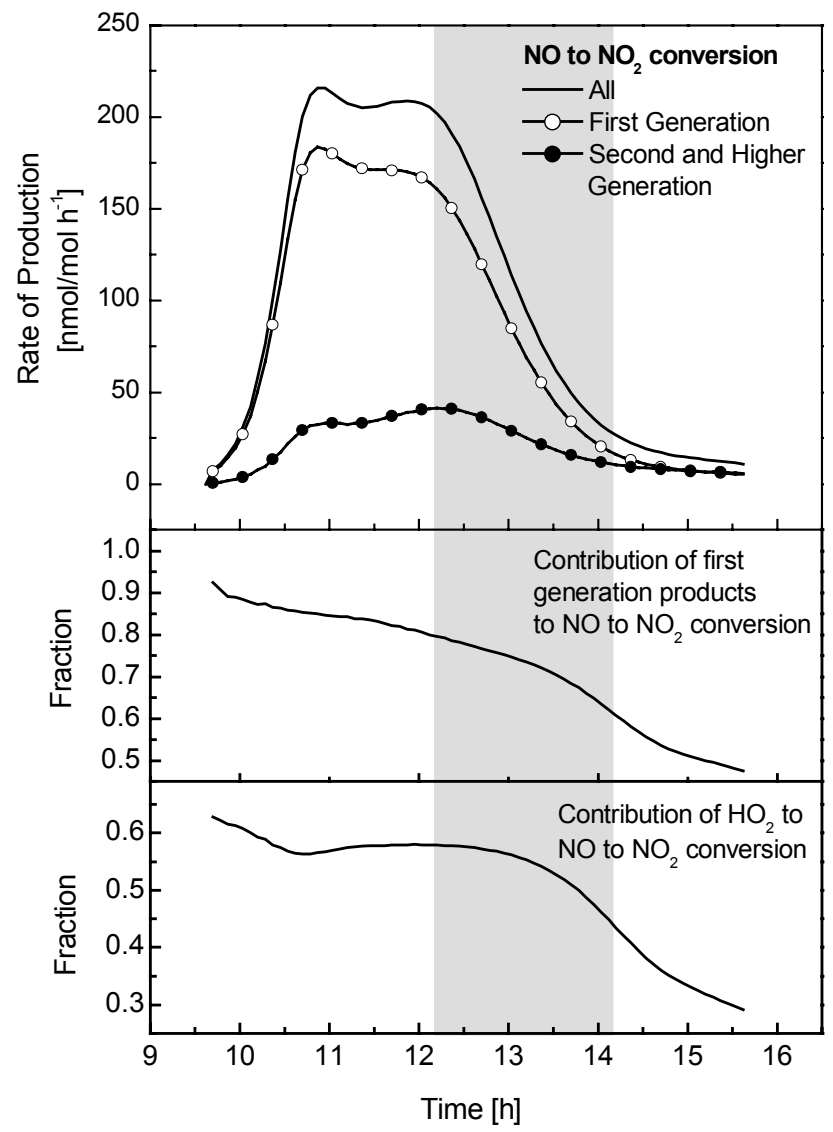

Fig. 8. Rate of $\mathrm{NO}$ to $\mathrm{NO}_{2}$ conversion calculated for toluene- $\mathrm{NO}_{\mathrm{x}}$ experiment 22/10/97. Panel 1: Time profile of $\mathrm{NO}$ to $\mathrm{NO}_{2}$ conversion, all processes, reactions of first generation products and reactions of higher generation products. Panel 2: Contribution of first generation products to $\mathrm{NO}$ to $\mathrm{NO}_{2}$ conversion. Panel 3: Contribution of $\mathrm{HO}_{2}$ to $\mathrm{NO}$ to $\mathrm{NO}_{2}$ conversion. Grey area indicates time period where the model over-predicts the $\mathrm{O}_{3}$ production in the experiment.

wall related reactions on the radical budget in the chamber is more uncertain at the end of the experiment owing to the complex mixture of organics and the high concentration of $\mathrm{NO}_{2}$ and $\mathrm{HNO}_{3}$ transferred to the walls over the course of the experiment. Further research is necessary to find out whether highly oxygenated reaction products or chamber wall related effects are responsible for the high radical production in the latter stages of the experiment.

\section{Ozone chemistry}

\subsection{Excess ozone}

The model over-prediction of the experimental ozone concentration in the 22/10/97 experiment is directly linked to the $\mathrm{NO}_{\mathrm{x}}$ chemistry and is reflected by an over-prediction of measured $\left[\mathrm{NO}_{2}\right]$. An increase in the $\mathrm{OH}$ concentration so 
that the simulated toluene decay matches the experimental decay leads to faster chemistry and a more rapid build-up of ozone, but, $\left[\mathrm{O}_{3}\right]$ at the end of the experiment is virtually unaffected (Fig. 3). As ozone is produced by the photolysis of $\mathrm{NO}_{2}$, the influence of reaction channels or of intermediates on ozone production is determined indirectly by their efficiency in converting $\mathrm{NO}$ into $\mathrm{NO}_{2}$. The second important parameter, which has a major effect on ozone production, is the conversion of $\mathrm{NO}_{\mathrm{x}}$ into sinks, such as $\mathrm{HNO}_{3}$ and PAN, which are stable over the time scale of the experiment. The capacity of a reaction channel to produce ozone is thus a function of its capacities to convert $\mathrm{NO}$ to $\mathrm{NO}_{2}$ and to sequester $\mathrm{NO}_{\mathrm{x}}$ into stable nitrogen compounds.

Table 2 shows that the dicarbonyl and epoxide routes are most efficient in converting $\mathrm{NO}$ to $\mathrm{NO}_{2}$. They produce 4.7 and 4.9 molecules $\mathrm{NO}_{2}$, respectively, per molecule of toluene oxidized. The benzaldehyde route with a branching ratio for ring-opening of less than $1 \%$ produces only few peroxy radicals and $\mathrm{NO}_{2}$ production is consequently very low with 1.3 molecules per molecule toluene oxidized. The epoxide and cresol routes show the largest efficiency for $\mathrm{NO}_{\mathrm{x}}$ consumption, removing 0.90 and 0.88 molecules $\mathrm{NO}_{\mathrm{x}}$, respectively, per molecule toluene oxidized. In the epoxide route the main sinks for $\mathrm{NO}_{\mathrm{x}}$ are $\mathrm{HNO}_{3}$ and PAN whereas in the cresol route the formation of nitro-hydroxy aromatics is most important. As a measure of the efficiency of ozone production we have calculated the number of $\mathrm{NO}$ to $\mathrm{NO}_{2}$ conversions per molecule $\mathrm{NO}_{\mathrm{x}}$ consumed. This number is highest for the dicarbonyl route as this route shows a strong $\mathrm{NO}$ to $\mathrm{NO}_{2}$ conversion in conjunction with a limited capacity to sequester $\mathrm{NO}_{\mathrm{x}}$ into stable $\mathrm{NO}_{\mathrm{y}}$ species. Cresol shows the lowest value owing to a small branching ratio for ring-opening and a high conversion of $\mathrm{NO}_{\mathrm{x}}$ into nitro-hydroxy aromatics.

The toluene mechanism contains 166 reactions converting $\mathrm{NO}$ to $\mathrm{NO}_{2}$, with 41 reactions accounting for $80 \%$ of the $\mathrm{NO}_{2}$ production. For simplification, we have lumped all processes into two groups relating respectively to the creation or oxidation of first generation products and to the oxidation of second or higher generation products. Figure 8 shows that, over the first $2.5 \mathrm{~h}$ of the experiment, more than $80 \%$ of the $\mathrm{NO}$ to $\mathrm{NO}_{2}$ conversion is caused by the production or by the oxidation of first generation products. In the time window when the model starts to over-predict the $\mathrm{O}_{3}$ production, from 12:30 until 14:30, the contribution of first generation products drops from 80 to $60 \%$ and the chemistry of secondary products becomes more important. Furthermore the $\mathrm{NO}$ to $\mathrm{NO}_{2}$ conversion by $\mathrm{RO}_{2}$ gains in importance. While at the beginning of the experiment more than $60 \%$ of the $\mathrm{NO}_{2}$ is produced by reaction of $\mathrm{NO}$ with $\mathrm{HO}_{2}$, its contribution drops to around $40 \%$ at 14:30. From this analysis we can conclude that during the time period when the model over-predicts ozone production, the chemistry that is linked to first generation products accounts, on average, for about two thirds of the total $\mathrm{NO}$ to $\mathrm{NO}_{2}$ conversion.

One option to correct the excess ozone formation would
Table 4. $\mathrm{NO}_{\mathrm{y}}$ budget calculated for the toluene- $\mathrm{NO}_{\mathrm{x}}$ experiment 22/10/97. Concentrations of $\mathrm{NO}_{\mathrm{y}}$ species are given for the end of the experiment at 15:00. Compounds are arranged into a group of "accessible" $\mathrm{NO}_{\mathrm{y}}$ species that can be measured with standard analytical equipment and a group of "problematic" $\mathrm{NO}_{\mathrm{y}}$ species, for which quantification is a major analytical challenge

\begin{tabular}{|c|c|c|c|}
\hline $\begin{array}{l}\mathrm{NO}_{\mathrm{y}} \\
\text { Compound }\end{array}$ & $\begin{array}{c}\text { Concen- } \\
\text { tration } \\
(\mathrm{nmol} / \mathrm{mol})\end{array}$ & $\begin{array}{c}\text { Contribution } \\
\text { to total } \\
\mathrm{NO}_{\mathrm{y}}(\%)\end{array}$ & Comment \\
\hline \multicolumn{4}{|l|}{ Accessible } \\
\hline $\mathrm{HNO}_{3}$ & 41.7 & 31.1 & \\
\hline PAN & 34.2 & 25.5 & \\
\hline $\mathrm{NO}_{2}$ & 3.9 & 2.9 & \\
\hline Nitrocresol & 0.5 & 0.4 & \\
\hline Total & & 59.9 & \\
\hline \multicolumn{4}{|l|}{$\underline{\text { Problematic }}$} \\
\hline $\begin{array}{l}\text { Nitro- } \\
\text { aromatics }\end{array}$ & 22.1 & 16.5 & 7 compounds \\
\hline $\mathrm{PAN}_{\mathrm{y}}$ & 18.4 & 13.7 & $\begin{array}{l}14 \text { compounds } \\
\mathrm{NO}_{2} \text { to } \mathrm{HNO}_{3}\end{array}$ \\
\hline Wall & 8.7 & 6.5 & $\begin{array}{c}\text { conversion on } \\
\text { walls }\end{array}$ \\
\hline Other & 4.6 & 3.5 & $\begin{array}{c}\mathrm{NO}_{\mathrm{y}} \\
\text { in aerosols }\end{array}$ \\
\hline
\end{tabular}

be to reduce the production of peroxy radicals, but this would also reduce $\mathrm{OH}$ formation and thus conflicts with the need to increase the oxidation capacity in the system. Therefore we suggest two processes that are likely to be responsible for the over-prediction of $\mathrm{O}_{3}$ by the model:

1. A missing source of $\mathrm{OH}$ involving no, or with only little, $\mathrm{NO}$ to $\mathrm{NO}_{2}$ conversion, such as ozonolysis of alkenes or isomerisation of peroxy-radicals in a similar mechanism to that during dimethyl ether oxidation as suggested by Jenkin et al. (1993). For example, for the latter, the peroxide-bicyclic peroxy radical, proposed as intermediate in the dicarbonyl route, could isomerise and break down, directly generating $\mathrm{OH}$ and $\alpha$ - and $\gamma$ dicarbonyls. This ring-opening mechanism does not include the two $\mathrm{NO}$ to $\mathrm{NO}_{2}$ conversions of the classical reaction sequence in which a peroxy radical is transformed into a carbonyl compound and $\mathrm{OH}$.

2. $\mathrm{NO}_{3}$ chemistry as a possible means of sequestering reactive nitrogen species by forming stable $\mathrm{NO}_{\mathrm{y}}$ compounds and at the same time producing $\mathrm{RO}_{\mathrm{x}}$ radicals (Wayne et al., 1991). The addition of $\mathrm{NO}_{3}$ to a double bond or an aromatic ring and subsequent reaction of the adduct with $\mathrm{O}_{2}$ can lead to a reaction sequence in which $\mathrm{NO}_{3}$ is tied-up into a nitrooxy-compound and 


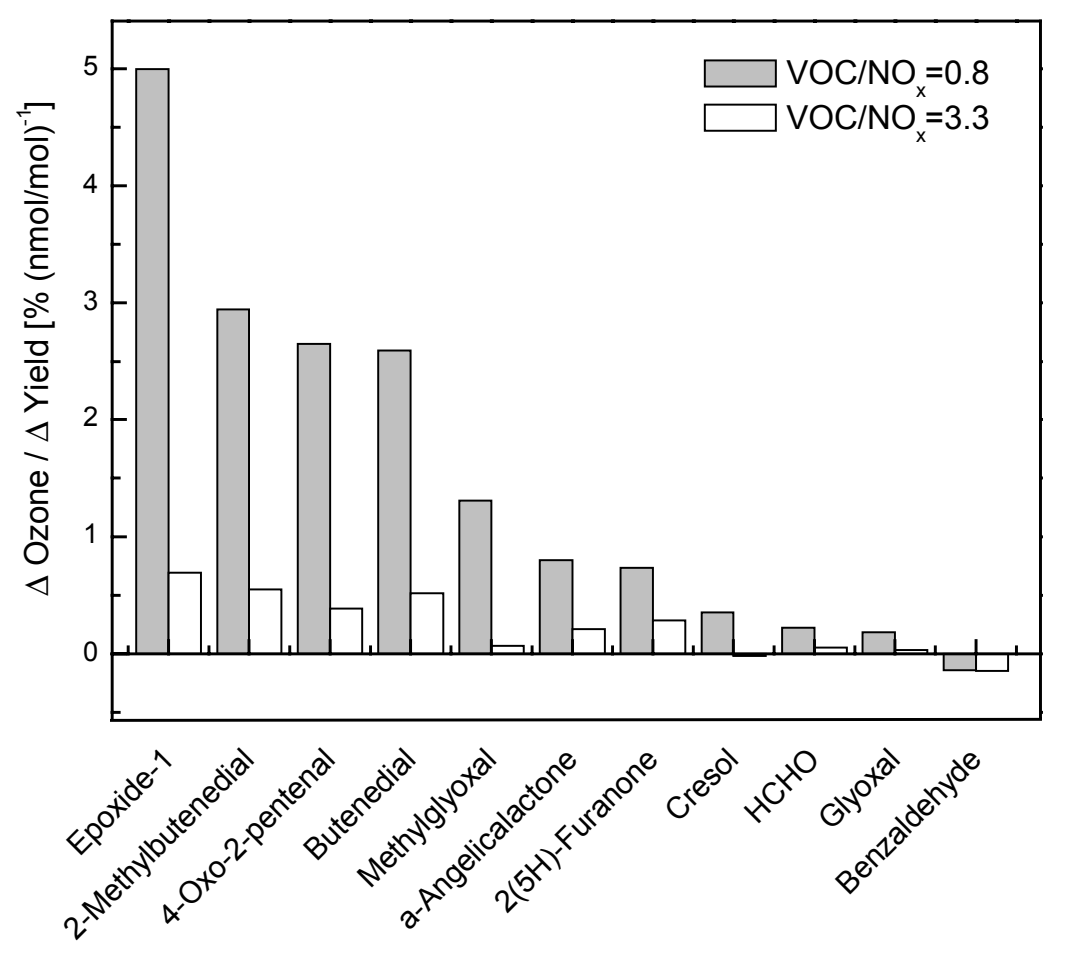

Fig. 9. Sensitivity of ozone to a change in the yields of intermediates calculated for the toluene- $\mathrm{NO}_{\mathrm{x}}$ experiment 22/10/97 (initial $\mathrm{VOC} / \mathrm{NO}_{\mathrm{x}}=3.3$ ) and for a "model experiment" with the same initial toluene concentration but a $\mathrm{VOC} / \mathrm{NO}_{\mathrm{x}}$ ratio of 0.8 . either $\mathrm{RO}_{2}$ is formed or $\mathrm{HO}_{2}$ is released. This type of reaction could help to increase the $\mathrm{RO}_{\mathrm{x}}$ production in the system and at the same time to reduce the $\mathrm{NO}_{2}$ concentration and therewith the $\mathrm{O}_{3}$ production.

A thorough understanding of the $\mathrm{NO}_{\mathrm{y}}$ budget is a prerequisite to elucidate the reasons behind the model overestimate of ozone. Table 4 shows the simulated $\mathrm{NO}_{\mathrm{y}}$ budget for the toluene experiment 22/10/97 at 15:00. Compounds are arranged into two groups: (1) $\mathrm{NO}_{\mathrm{y}}$ species that can be measured with standard analytical equipment and (2) $\mathrm{NO}_{\mathrm{y}}$ species for which quantification is a major analytical challenge. The contributions of $\mathrm{HNO}_{3}$ and PAN to the $\mathrm{NO}_{\mathrm{y}}$ budget are $31.1 \%$ and $25.5 \%$, respectively. Including $\mathrm{NO}_{2}$ and nitrocresol, compounds of the first group make up about $59.9 \%$ of total calculated $\mathrm{NO}_{\mathrm{y}}$. In the second group, nitroaromatics, mainly products of the cresol route, contribute $16.5 \%$. A further $13.7 \%$ of the reactive $\mathrm{NO}_{\mathrm{x}}$ is sequestered into PAN $_{y}$, which is represented in the model by 14 different compounds. Minor fractions of $\mathrm{NO}_{\mathrm{x}}$ are converted to $\mathrm{HNO}_{3}$ by wall reactions or go into the aerosol phase.

Owing to the low concentrations and the technical difficulties concerning the measurements of "problematic" $\mathrm{NO}_{\mathrm{y}}$ compounds it is not feasible to obtain experimental closure in the $\mathrm{NO}_{\mathrm{y}}$ budget by more than about $60 \%$. However, experimental data on the most prominent species of each compound class is crucial to the identification of potential missing sinks of $\mathrm{NO}_{\mathrm{x}}$ in the model.

\section{$5.2 \mathrm{O}_{3}$ sensitivities}

An important parameter describing the tendency of a compound to produce $\mathrm{O}_{3}$ is the $\mathrm{O}_{3}$ sensitivity $\mathrm{S}_{3}$, that describes the change in $\left[\mathrm{O}_{3}\right]$ caused by a change in a single model parameter. $\mathrm{S}_{\mathrm{O}_{3}}$ was calculated by brute force, using the yields of intermediates as variables:

$\mathrm{S}_{\mathrm{O}_{3}}=\frac{\Delta\left[\mathrm{O}_{3}\right]}{\Delta \text { [yield of intermediate }]}$.

For each run the yield of a single compound was changed by $20 \%$ and $\Delta\left[\mathrm{O}_{3}\right]$ calculated as the difference in the integrals over the $\mathrm{O}_{3}$ concentration time profiles of the run with the increased yield and the base run. The $\mathrm{O}_{3}$ sensitivities were normalized and given as percentage change in the ozone concentration caused by a change of $1 \mathrm{nmol} / \mathrm{mol}$ in the yield of an intermediate. We have carried out sensitivity calculations for the 22/10/97 experiment with an initial $\mathrm{VOC} / \mathrm{NO}_{\mathrm{x}}$ ratio of 3.3 and for a "model experiment" with identical initial [toluene] but a $\mathrm{VOC} / \mathrm{NO}_{\mathrm{x}}$ ratio of 0.8 .

Figure 9 shows that $\mathrm{O}_{3}$ has the highest sensitivities to changes in the concentration of epoxide-1, conjugated $\gamma$ dicarbonyls and methylglyoxal. The sensitivities for cresol, formaldehyde and glyoxal are comparatively low and for benzaldehyde they are even negative, due to its low $\mathrm{OH}$ production rate and low tendency to convert $\mathrm{NO}$ into $\mathrm{NO}_{2}$. There is a marked increase in the sensitivities of compounds, apart from benzaldehyde, at higher $\mathrm{NO}_{\mathrm{x}}$ concentrations: on average, the sensitivities for epoxide- 1 and conjugated $\gamma$ dicarbonyls are increased by a factor of 6 . At a $\mathrm{VOC} / \mathrm{NO}_{\mathrm{x}}$ 


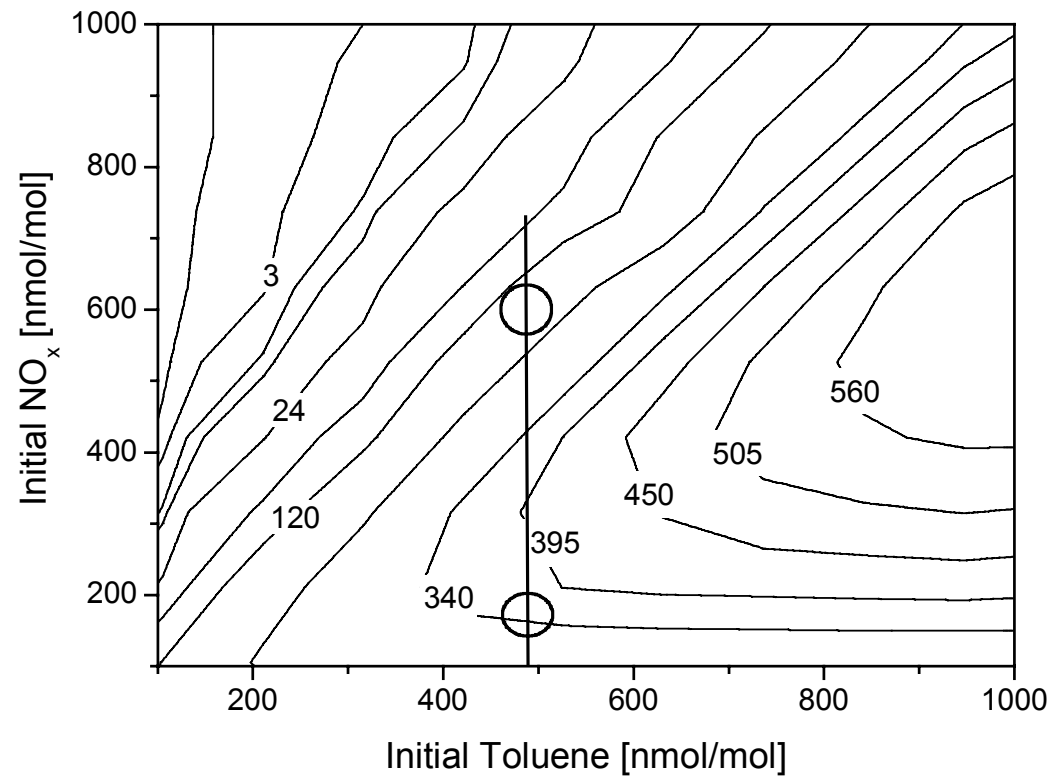

Fig. 10. Ozone isopleth plot for a toluene- $\mathrm{NO}_{\mathrm{x}}$ system under chamber conditions. The maximum ozone concentration (in units of $\mathrm{nmol} / \mathrm{mol}$ ), during the course of an experiment is plotted as function of the initial $\mathrm{NO}_{\mathrm{x}}$ and toluene concentrations. The circles indicate the conditions for the 22/10/97 experiment $\left(\mathrm{VOC} / \mathrm{NO}_{\mathrm{x}}\right.$ ratio of 3.3) and the "model experiment" with a $\mathrm{VOC} / \mathrm{NO}_{\mathrm{x}}$ ratio of 0.8 . ratio of 0.8 , the system is obviously VOC limited and the $\mathrm{O}_{3}$ concentration is consequently much more sensitive to a change in the concentration of intermediates than under low $\mathrm{NO}_{\mathrm{x}}$ conditions.

We have calculated an ozone isopleth plot for toluene$\mathrm{NO}_{\mathrm{x}}$ chamber experiments to check if the concept of VOC and $\mathrm{NO}_{\mathrm{X}}$ limited regimes is applicable to these systems. As the $\mathrm{VOC} / \mathrm{NO}_{\mathrm{x}}$ ratio strongly increases during the course of an experiment (Fig. 3), we plotted the maximum ozone concentration as a function of the initial toluene and $\mathrm{NO}_{\mathrm{x}}$ concentration (Fig. 10). The circles indicate the conditions for the $22 / 10 / 97$ experiment $\left(\mathrm{VOC} / \mathrm{NO}_{\mathrm{x}}\right.$ ratio of 3.3 ) and the "model experiment" with a $\mathrm{VOC} / \mathrm{NO}_{\mathrm{x}}$ ratio of 0.8 . Depending on the initial conditions, the maximum ozone concentration in chamber experiments shows a behaviour analogous to that described in isopleth plots calculated for atmospheric conditions. At low $\mathrm{NO}_{\mathrm{x}}$ concentrations the ozone production is $\mathrm{NO}_{\mathrm{x}}$ limited and with increasing $\mathrm{NO}_{\mathrm{x}}$ concentration the system passes a regime with maximum ozone productivity. At very high $\mathrm{NO}_{\mathrm{x}}$ concentrations the system is VOC limited and the ozone concentration decreases with increasing $\mathrm{NO}_{\mathrm{x}}$ concentrations. For the validation of atmospheric models, smog-chamber experiments with low $\mathrm{NO}_{\mathrm{x}}$ concentrations that come close to atmospheric conditions are preferred. However, the $\mathrm{NO}_{\mathrm{x}}$ dependency of the ozone sensitivity suggests that experiments at high $\mathrm{NO}_{\mathrm{x}}$ levels, in the VOC limited region, are most suited to study the robustness of mechanisms with regards to the $\mathrm{O}_{3}$ production.

To obtain more information on the impact of intermediates on the reactivity of the toluene system we have calculated the sensitivities of $\mathrm{OH}$ to a change in the yields of 25 first and second generation products. Figure 11 shows the correlation between the $\mathrm{O}_{3}$ and $\mathrm{OH}$ sensitivities for the two simulations with an initial $\mathrm{VOC} / \mathrm{NO}_{\mathrm{x}}$ ratio of $3.3(22 / 10 / 97$ experiment) and an initial $\mathrm{VOC} / \mathrm{NO}_{\mathrm{x}}$ ratio of 0.8 . At the low VOC/NO $\mathrm{Na}_{\mathrm{x}}$ ratio the sensitivities for $\mathrm{OH}$ and $\mathrm{O}_{3}$ show a distinct correlation; the $\mathrm{NO}$ to $\mathrm{NO}_{2}$ conversion clearly depends linearly on the $\mathrm{OH}$ yield from a compound. This implies that an over-prediction of the ozone concentration concurrent with an under-prediction of the reactivity in the toluene system at low $\mathrm{VOC} / \mathrm{NO}_{\mathrm{x}}$ (VOC-limited) is in contradiction with the calculated correlation between the sensitivities and would point to a photooxidation process that is not represented by any of the 25 compounds depicted in Fig. 11. At a VOC/NO ratio of 3.3 the $\mathrm{OH}$ and $\mathrm{O}_{3}$ sensitivities no longer show a distinct correlation. In this $\mathrm{NO}_{\mathrm{x}}$ limited regime the overall effect of a radical initiation process on the $\mathrm{OH}$ budget becomes also a function of the propensity of the radicals to terminate via peroxy-peroxy reaction. An over-prediction of the ozone concentration concurrent with an under-prediction of the $\mathrm{OH}$ production in the toluene system is no longer in contradiction with the results of the sensitivities analysis. As the ratio of $\mathrm{OH}$ to $\mathrm{O}_{3}$ sensitivities of the intermediates varies over a wide range at low $\mathrm{NO}_{\mathrm{x}}$ concentrations, an increase of yields for compounds with high $\mathrm{OH}$ but low $\mathrm{O}_{3}$ sensitivities could bring simulations into agreement with experimental results. The sensitivity analysis shows that the toluene reaction system at high $\mathrm{VOC} / \mathrm{NO}_{\mathrm{x}}\left(\mathrm{NO}_{\mathrm{x}}\right.$-limited) ratios is far more complex and difficult to understand than under low $\mathrm{VOC} / \mathrm{NO}_{\mathrm{x}}$ (VOC-limited) conditions.

\section{Conclusions and implications}

In this study we have presented a number of modelling tools that help to improve our understanding of the shortcomings in detailed atmospheric mechanisms and that provide crucial 

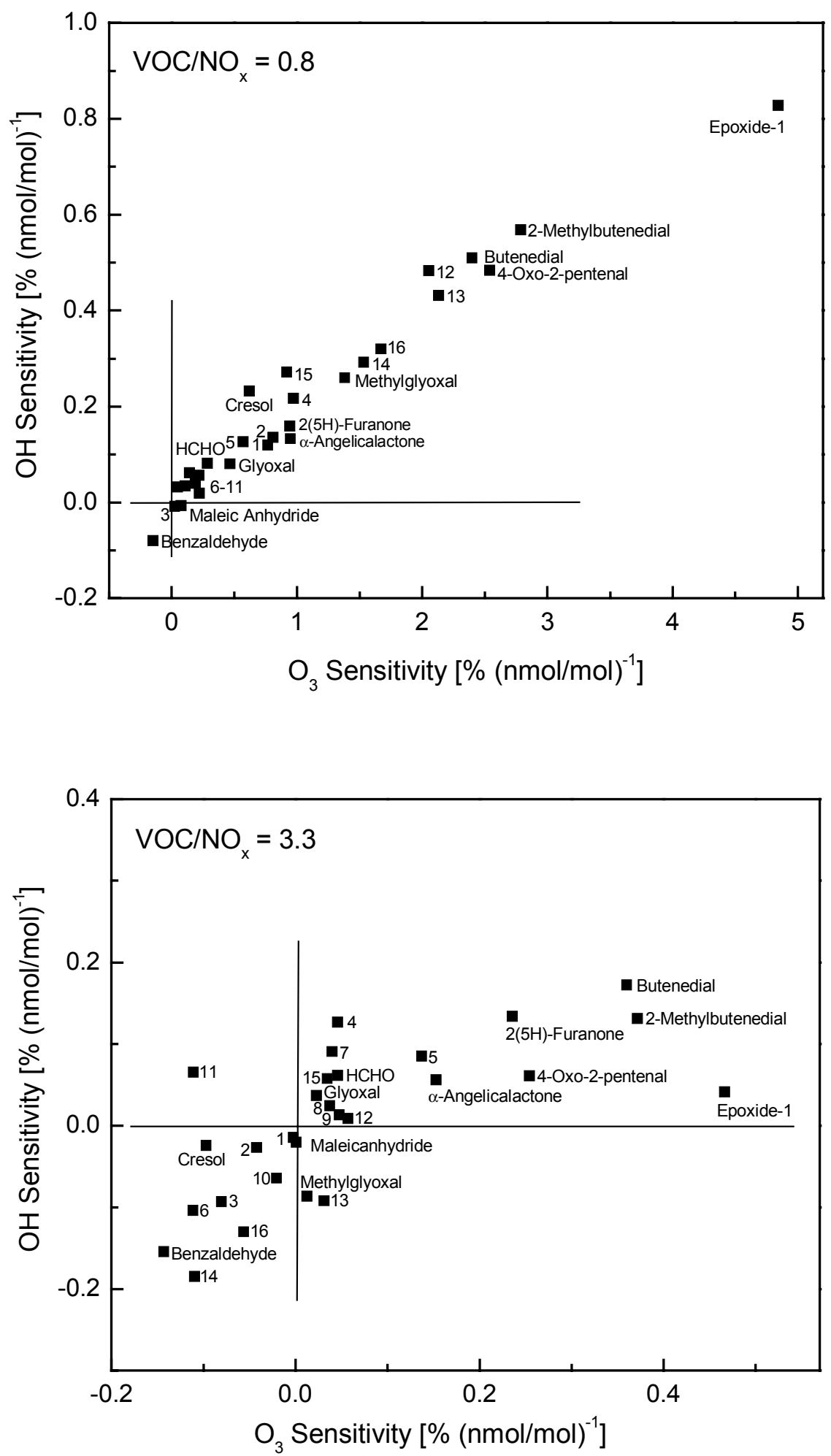

Fig. 11. Correlation between $\mathrm{O}_{3}$ and $\mathrm{OH}$ sensitivities for first and second generation products in the toluene system. Correlation is shown for two different simulations with initial $\mathrm{VOC} / \mathrm{NO}_{\mathrm{x}}$ ratios of 0.8 and 3.3 (22/10/97 experiment). Key to species: 1) 2,3-epoxybutandial; 2) methyl-1,4-benzoquinone; 3) acetaldehyde; 4) 4-hydroxy-3-methyl-cyclohexa-2,5-dienone; 5) 4-oxopent-2-enoic acid; 6) 2-hydroxy3-oxo-butanal; 7) trioxopropane; 8) 4-hydroxy-dihydro-furan-2,3-dione; 9) 4-hydroxy-5-methyl-dihydro-furan-2,3-dione; 10) methylmaleic anhydride; 11) 3-methyl-2,5-dioxo-hex-3-enedial; 12) 2-hydroxy-3,4-dioxo-pentanal; 13) 2,3,4-trioxopentanal; 14) 2,3-dioxobutanal; 15) glyoxylic acid; 16) 2,3-epoxy-4-hydroxy-5,6-dioxo-heptanal. 
information for the design of future validation experiments. We have taken toluene for our case study. A comparison between simulation and smog-chamber data for a toluene- $\mathrm{NO}_{\mathrm{x}}$ system revealed two major shortcomings in the mechanism: (1) a severe under-prediction of the radical production by about $44 \%$ and (2) an over-prediction of the ozone concentration by $55 \%$. By calculating the $\mathrm{RO}_{\mathrm{x}}$ budget of the system and $\mathrm{O}_{3}$ and $\mathrm{OH}$ sensitivities we gained information on compounds and processes that govern the oxidation capacity in the toluene- $\mathrm{NO}_{\mathrm{x}}$ system. Major findings are:

1. The $\mathrm{RO}_{\mathrm{x}}$ budget calculations show that methylglyoxal, glyoxal, HCHO, epoxide-1, and conjugated $\gamma$ dicarbonyls are the dominant radical sources in the system. Radical production at the beginning of the experiments can only be explained by ring-opening intermediates, such as epoxide-1 or the conjugated $\gamma$ dicarbonyls, which have very high photolysis rates and are strong sources of new radicals. The photochemistry of this class of compounds is very poorly understood and the chemistry implemented in the toluene mechanism is very speculative. More experimental data on the co-products of glyoxal and methylglyoxal as well as the putative epoxide compounds are essential for a further improvement of the mechanism.

2. The over-prediction of ozone by the model is a more intricate problem as ozone production is linked to $\mathrm{RO}_{\mathrm{x}}$ radical transformation. By calculating the $\mathrm{NO}_{\mathrm{x}}$ budget it could be shown that, until $\mathrm{O}_{3}$ reaches the maximum concentration, about two thirds of the $\mathrm{NO}$ to $\mathrm{NO}_{2}$ conversion is linked to the production and oxidation of first generation products. The compounds which have the highest ozone sensitivities are epoxide- 1 and the conjugated $\gamma$-dicarbonyls. To explain the ozone overprediction we need to understand the interaction between radical production and the ozone creation potential of these compound classes. A general problem is that a reduction in $\mathrm{NO}$ to $\mathrm{NO}_{2}$ conversion from a decrease in the peroxy radical formation will inevitably lead to less $\mathrm{OH}$ production and is therefore incompatible with the need to increase the oxidation capacity in the toluene system. We suggest two possible processes that might be responsible for the high reactivity in the experimental system and the concomitant comparatively low $\mathrm{O}_{3}$ production: (i) processes that generate $\mathrm{OH}$ directly without or with only little $\mathrm{NO}$ to $\mathrm{NO}_{2}$ conversion and (ii) $\mathrm{NO}_{3}$ chemistry that sequesters reactive nitrogen oxides into stable $\mathrm{NO}_{\mathrm{y}}$ compounds and at the same time produces $\mathrm{HO}_{\mathrm{x}}$ radicals. As measurement techniques are available for only a few of the $\mathrm{NO}_{\mathrm{x}}$ sinks, such as $\mathrm{HNO}_{3}$, PAN-type compounds, nitroaromatics and alkylnitrates, closure of the $\mathrm{NO}_{\mathrm{y}}$ budget is not feasible in the near future. However, measurements of a major representative of each compound class are essential to explain the $\mathrm{O}_{3}$ over-prediction.
3. A sensitivity analysis has shown that the sensitivity of $\mathrm{O}_{3}$ to a change in the concentration of intermediates is highest at high $\mathrm{NO}_{\mathrm{x}}$ concentration. Thus, validation experiments in the VOC limited regime are particularly suited to test mechanisms on major shortcomings in their $\mathrm{O}_{3}$ productivity. At low $\mathrm{NO}_{\mathrm{x}}$ concentrations the $\mathrm{O}_{3}$ and $\mathrm{OH}$ sensitivities no longer show a distinct correlation and photochemical processes become much more complex as peroxy-peroxy termination gains importance and becomes an additional parameter influencing the $\mathrm{OH}$ and $\mathrm{O}_{3}$ production potential of a compound.

For a further improvement of the toluene mechanism, quantification of the co-products (conjugated $\gamma$-dicarbonyls) of glyoxal and methylglyoxal and the major intermediates in the putative epoxide route will be crucial. Furthermore, the sub-mechanisms describing the photochemistry of those compounds that have, according to our current knowledge, the highest impact on $\mathrm{OH}$ and $\mathrm{O}_{3}$ formation should be validated against single-component experiments. A crucial question is how much $\mathrm{NO}_{\mathrm{x}}$ is sequestered into nitro-organic compounds. With more information on the photochemistry of intermediates and the $\mathrm{NO}_{\mathrm{y}}$ budget emerging, it will be possible to gradually improve the toluene mechanism so that $\mathrm{OH}$ as well as $\mathrm{O}_{3}$ can be reliably predicted over a broad range of $\mathrm{NO}_{\mathrm{x}}$ concentrations, from highly polluted to remote conditions, as is essential for atmospheric models.

Acknowledgements. The authors thank A. Henderson, M. MartinReviejo and R. Volkamer for helpful discussions. MEJ gratefully acknowledges the UK Natural Environment Research Council, NERC, for support via a Senior Research Fellowship (NERK/K/S/2000/00870). This work was part of the European Union project EXACT, contract No. EVK2-CT-1999-00053.

\section{References}

Atkinson, R., Carter, W. P. L., Darnall, K. R., Winer, A. M., and Pitts, Jr., J. N.: A smog-chamber and modelling study of the gas phase $\mathrm{NO}_{\mathrm{x}}$-air photooxidation of toluene and the cresols, Int. J. Chem. Kinet., 12, 779-834, 1980.

Atkinson, R.: A structure-activity relationship for the estimation of rate constants for the gas-phase reactions of $\mathrm{OH}$ radicals with organic compounds, Int. J. Chem. Kinetics., 19, 799-828, 1987.

Atkinson, R.: Gas-phase tropospheric chemistry of organic compounds, J. Phys. Ref. Data, Monograph, 2, 47-59, 1992.

Bartolotti, L. J. and Edney, E. O.: Density functional theory derived intermediates from the $\mathrm{OH}$ initiated atmospheric oxidation of toluene, Chem. Phys. Lett., 245, 119-122, 1995.

Berndt, T., Böge, O., and Herrmann, H.: On the formation of benzene oxide / oxepin in the gas-phase of $\mathrm{OH}$ radicals with benzene, Chem. Phys. Lett., 314, 435-442, 1999.

Bierbach, A., Barnes, I., Becker, K. H., and Wiesen, E.: Atmospheric chemistry of unsaturated carbonyls: Butenedial, 4-oxo2-pentenal, 3-hexene-2,5-dione, maleic anhydride, 3H-furan-2one, and 5-methyl-3H-furan-2-one, Environ. Sci. Technol., 28, 715-729, 1994. 
Bohn, B. and Zetzsch, C.: Gas-phase reaction of the OH-benzene adduct with $\mathrm{O}_{2}$ : Reversibility and secondary formation of $\mathrm{HO}_{2}$, Phys. Chem. Chem. Phys., 1, 5097-5107, 1999.

Bohn, B.: Formation of peroxy radicals from $\mathrm{OH}$-toluene adducts and $\mathrm{O}_{2}$, J. Phys. Chem. A, 105, 6092-6101, 2001.

Derwent, R. G., Jenkin, M. E., and Saunders, S. M.: Photochemical ozone creation potentials for a large number of reactive hydrocarbons under European conditions, Atmos. Environ., 30, 181-199, 1996.

Derwent, R. G., Jenkin, M. E., Saunders, S. M., and Pilling, M. J.: Photochemical ozone creation potentials for organic compounds in northwest Europe calculated with a Master Chemical Mechanism, Atmos. Environ., 32, 2429-2441, 1998.

Ghigo, G. and Tonachini, G.: From benzene to muconaldehyde: Theoretical mechanistic investigation on some tropospheric oxidation channels., J. Am. Chem. Soc., 121, 8366-8372, 1999.

Jang, M. and Kamens, R. M.: Characterization of secondary aerosol from the photooxidation of toluene in the presence of $\mathrm{NO}_{\mathrm{x}}$ and 1-propene, Environ. Sci. Technol., 35, 3626-3639, 2001.

Jenkin, M. E., Hayman, G. D., Wallington, T. J., Hurley, M. D., Ball, J. C., Nielsen, O. J., and Ellermann, T.: Kinetic and mechanistic study of the self reaction of $\mathrm{CH}_{3} \mathrm{OCH}_{2} \mathrm{O}_{2}$ radicals at room temperature, J. Phys. Chem., 97, 11 712-11 723, 1993.

Jenkin, M. E. and Clemitshaw, K. C.: Ozone and other secondary photochemical pollutants: chemical processes governing their formation in the planetary boundary layer, Atmos. Environ., 34, 2499-2527, 2000.

Jenkin, M. E., Saunders, S. M., Wagner, V., and Pilling, M.: Protocol for the development of the Master Chemical Mechanism, MCM v3 (Part B): tropospheric degradation of aromatic volatile organic compounds, Atmos. Chem. Phys. Discuss., 2, 19051938, 2002.

Klotz, B., Barnes, I., Becker, K. H., and Golding, B. T.: Atmospheric chemistry of benzene oxide/oxepin, J. Chem. Soc., Faraday Trans., 93, 1507-1516, 1997.

Klotz, B., Sørensen, S., Barnes, I., Becker, K. H., Etzkorn, T., Volkamer, R., Platt, U., Wirtz, K., and Montserrat, M.-R.: Atmospheric oxidation of toluene in a large-volume outdoor photoreactor: In situ determination of ring-retaining product yields, J. Phys. Chem., 102, 10 289-10 299, 1998.

Klotz, B., Barnes, I., Golding, B. T., and Becker, K.-H.: Atmospheric chemistry of toluene-1,2-oxide/2-methyloxepin, Phys. Chem. Chem. Phys., 2, 227-235, 2000.

Kwok, E. and Atkinson, R.: Estimation of hydroxyl radical rate constants for gas-phase organic compounds using a structurereactivity relationship: an update, Atmos. Environ., 29, 1685$1695,1995$.

Liang, J. and Jacobson, M. Z.: Comparison of a 4000-reaction chemical mechanism with the carbon bond IV and an adjusted carbon bond IV-EX mechanism using SMVGEAR II, Atmos. Environ., 34, 3015-3026, 2000.

Liu, X. Y., Jeffries, H. E., and Sexton, K. G.: Atmospheric photochemical degradation of 1,4-unsaturated dicarbonyls, Environ. Sci. Technol., 33, 4212-4220, 1999.

Motta, F., Ghigo, G., and Tonachini, G.: Oxidative degradation of benzene in the troposphere. Theoretical mechanistic study of the formation of unsaturated dialdehydes and dialdehyde epoxides, J. Phys. Chem. A, 106, 4411-4422, 2002.

Olariu, R. I., Klotz, B., Barnes, I., Becker, K. H., and Mocanu, R.: FT-IR study of the ring-retaining products from the reaction of $\mathrm{OH}$ radicals with phenol, o-, m-, and p-cresol, Atmos. Environ., 36, 3685-3697, 2002.

Saunders, S. M., Jenkin, M. E., Derwent, R. G., Pilling, M. J.: Protocol for the development of the Master Chemical Mechanism, MCM v3 (Part A): tropospheric degradation of non-aromatic volatile organic compounds, Atmos. Chem. Phys. Discuss., 2, 1847-1903, 2002.

Seuwen, R. and Warneck, P.: Oxidation of toluene in $\mathrm{NO}_{\mathrm{x}}$ free air: Product distribution and mechanism, Int. J. Chem. Kinet., 28, 315-332, 1996.

Smith, D. F., McIver, C. D., and Kleindienst, T. E.: Primary product distribution from the reaction of hydroxyl radicals with toluene at ppb $\mathrm{NO}_{\mathrm{x}}$ mixing ratios, J. Atmos. Chem., 30, 209-228, 1998.

Sørensen, S., Barnes, I., and Becker, K. H.: Photolysis of unsaturated 1,4-dicarbonyls under atmospheric conditions in the European photoreactor (EUPHORE), Environ. Sci. and Poll. Res., 5, 159, 1998.

Volkamer, R., Platt, U., and Wirtz, K.: Primary and secondary glyoxal formation from aromatics: Experimental evidence for the bicycloalkyl-radical pathway from benzene, toluene, and $\mathrm{p}$ xylene, J. Phys. Chem. A, 105, 7865-7874, 2001.

Volkamer, R., Klotz, B., Barnes, I., Imamura, T., Wirtz, K., Washida, N., Becker, K. H., and Platt, U.: OH-initiated oxidation of benzene: Part 1. Phenol formation under atmospheric conditions, Phys. Chem. Chem. Phys., 4, 1598-1610, 2002.

Wayne, R. P., Barnes, I., Biggs, P., Burrows, J. P., Canosa-Mas, C. E., Hjorth, J., Le Bras, G., Moortgat, G. K., Perner, D., Poulet, G., Restelli, G., and Sidebottom, H.: The nitrate radical: Physics, chemistry, and the atmosphere, Atmos. Environ., 25A, 1-203, 1991.

Yu, J. and Jeffries, H.: Atmospheric photooxidation of alkylbenzenes - II Evidence of formation of epoxide intermediates, Atmos. Environ., 31, 2281-2287, 1997.

Yu, J., Jeffries, H., and Sexton, K. G.: Atmospheric photooxidation of alkylbenzenes - I. Carbonyl product analyses, Atmos. Environ., 31, 2261-2280, 1997. 